\title{
Mars-Relevant Field Experiences in Morocco: The Importance of Spatial Scales and Subsurface Exploration
}

\author{
Akos Kereszturi, Zsuzsanna Kapui, Gian Gabrielle Ori, ${ }^{3,4}$ Kamal Taj-Eddine, and Gabor Ujvari ${ }^{2}$
}

\begin{abstract}
During field work at the Ibn Battuta Mars analogue sites, two research questions were analyzed: (1) How do we identify sampling sites using remote and local imaging and (2) what kind of information can be gained from shallow subsurface exploration? While remote images help in targeting field activities in general, the connection between observations at different spatial scales for different rocky desert terrain types is not well established; in this, focused comparison of remote in situ images of well-selected analogues would help a great deal. Dried up lake beds as discerned in remotely acquired data may not show signatures of past water activity, while shallow subsurface exploration could reveal the lacustrine period. Acquisition of several satellite images of the same terrain under different geometries would help to support the planning of such in situ work. The selection of appropriate sampling sites in fluvial settings could be improved by analyzing long, meter-high, open-air outcrops that formed during most recent fluvial episodes. Such settings are abundant on Earth and could be present on Mars but may be just below the resolution of available data. By using 20-30-cm-deep excavations, shallow subsurface exploration could reveal the last period of geological history that would have been unattainable by surface observation alone. Aggregates embedded in the original strata or from heavily pulverized samples could not be identified; only weakly fragmented samples viewed right after acquisition showed aggregates, and thus, the close-up imager (CLUPI) on the ExoMover might provide information on cementation-related aggregation on the observing plate before crushing. The mechanical separation of different size grains (mainly clays and attached minerals) would also support the identification of individual components. To maximize context information during subsurface exploration, rover imaging should be accomplished before crushing; however, currently planned imaging may not be ideal for this. Key Words: Mars analogues-Ibn Battuta Centre-Subsurface exploration-Field work. Astrobiology 18, xxx-xxx.
\end{abstract}

\section{Introduction}

$\mathbf{M}$ ARS ANALOGUE STUDIES on Earth support the planning (Baliva et al., 1999; Farr et al., 2002; Berczi et al., 2007; Hargitai, 2009; Orzechowska et al., 2011; Orgel et al., 2014; Amador et al., 2015), testing (Groemer et al., 2010, 2014; Losiak et al. 2014), and realization of Mars missions (Golombek and Rapp, 1997), and help to widen and deepen our understanding of various processes and conditions beyond Earth (Barlow et al., 2011; El-Baz et al., 1979; Wentworth et al., 2005; Warren-Rhodes et al., 2007; Catling et al., 2010; Hesse, 2012). Among these field sites, accessible desert analogues (Komatsu et al., 2007; Ori et al., 2014b) provide ideal locations for the preparation and testing of methodologies of planetary surface exploration. In the present study, we summarize field experiences at the Ibn Battuta Mars analogue field sites in Morocco, with emphasis on the next European Mars surface mission: the ExoMars rover (Vago and Exomars Project Team, 2010; Vago et al., 2015). Thus, we place more emphasis on methodological means as opposed to resolution of scientific issues.

This work focuses on two main research questions: (1) How to improve the targeting of in situ work by using different spatial-scale information, including remote sensing and local nearby images? The underlying hypothesis is that the proper interpretation of outcrops and understanding of

\footnotetext{
${ }^{1}$ Konkoly Thege Miklos Astronomical Institute, Research Centre for Astronomy and Earth Sciences, Budapest, Hungary.

${ }^{2}$ Institute for Geological and Geochemical Research, Research Centre for Astronomy and Earth Sciences, Budapest, Hungary.

${ }^{3}$ Ibn Battuta Centre, Cadi Ayyad University, Marrakech, Morocco.

${ }^{4}$ International Research School on Planetary Sciences, Pescara, Italy.
} 
the local geology maximize the outcome from laboratorybased sample analysis. (2) What type of information could be gained by shallow subsurface exploration on Mars at analogue sites? Forthcoming Mars missions will use drilling and subsurface sampling (to avoid the weathering effect of solar ultraviolet, atmospheric oxidants, and partly ionizing particle radiation at the surface), which will include ExoMars rover drilling. However, it is not yet fully understood how fruitful subsurface sampling on Mars will be or what characteristic settings will be revealed in the shallow subsurface. It is possible that, due to the slow rate of surface weathering and erosion on Mars, some geological settings in the subsurface are well preserved, in particular older sedimentary terrains. It would be advantageous, however, to demonstrate subsurface exploration procedures by investigating analogue sites in slowly changing terrestrial desert regions.

Furthermore, a general field exploration was also done with an emphasis on methodological issues, including questions as to whether any differences existed between in situ and satellite-based remote image analysis of Mars-like terrains in the study area, and how the different spatial-scale observations can be integrated and fit into a general picture.

The expedition crossing the Atlas and Anti-Atlas was realized between 15 and 21 of September 2016 with the support of the Europlanet RI H2020 project. The Ibn Battuta Centre as a facility of the Europlanet Research Infrastructure was established in 2006 by the International Research School of Planetary Sciences (IRSPS) at Pescara, Italy, to prepare and execute scientific analogue field tests of various instruments and methods for missions to Mars and partly to the Moon (Ori et al., 2015). Descriptions of the major characteristics of these sites and the already realized projects there can be found in accompanying articles of this special issue and in previous publications (Ori et al., 2009, 2011, 2013).

Ibn Battuta is specific among other Mars analogue sites in a sense that there are a large number of different sedimentary environments and sediment types in the region, which experienced substantial climatic changes in the last million years that included dry and wet periods (Ori et al., 2014a). Among these environments, recent wadis (Nicoll and Komatsu, 1999) and different stony desert types with large morphological varieties occur. The martian surface is often characterized by quite a large number of boulders of different sizes (McSween et al., 1999) together with dust and duricrust covered surface units. The spatial distribution of boulders is partly related to local outcrops based on the observations of the Opportunity rover (Weitz et al., 2006), and aside from impact ejection, weathering has likely contributed to the production of surface debris cover on Mars. The terrains at Ibn Battuta Centre provide ideal conditions to gain insight into the formation of these rock deserts and determine the methodological requirements for analyzing such aeolian surface features on Mars.

In the present study, we provide examples on how the geological/morphological features should be analyzed on different spatial scales (Jolliff et al., 2002) and discuss how the sampling of targets on Mars should be performed. We also put emphasis on the shallow subsurface region (down to $10-30 \mathrm{~cm})$, as this depth is getting more accessible by present and future missions (Kereszturi, 2012). In this study, a great step forward is expected from drilling activities of the ESAIKI (European Space Agency-Russian Space Research In- stitute) ExoMars 2018 rover (EXM) missions and from the ground penetrating radar and neutron spectrometer onboard ExoMars that have the capability to survey the shallow subsurface down to about $2 \mathrm{~m}$ depth. This analogue research work is the continuation of an earlier attempt (Kereszturi et al., 2016) to identify what type of geological and past water-related information could be gained by EXM using analogue observations. Understanding the geological history will be crucial to proper planning and the overall focus of in situ research in astrobiology on Mars, including reconstruction of past conditions and the identification of the role of water. Earth analogue studies, in particular, will provide crucial information for future endeavors on (Rothschild, 1990; McKay et al., 2002; Cabrol et al., 2007; Hock et al., 2007; Preston and Dartnell, 2014).

\section{Methods}

The field work in Morocco was supported by the Ibn Battuta Centre and included travel by way of two jeeps, on and off road, with GPS coordinates. During the field activities, cameras, hammers, spades, and a hand driller were used. The activity started with satellite image analyses and continued in the field with a rough characterization (short visual inspection) on-site. If a particular geological site proved to be attractive (observable surface features that would provide insight into past formation processes such as layering or signatures of liquid water or other transport processes), a detailed workup was initiated, which included photo documentation at different spatial scales (from context to small-scale sedimentary features), excavation and profile cleaning of outcrops with spade shovels, drilling (at four sites altogether) and optical scanning of borehole-walls with an A4-Tech PK-910H web camera, and finally, sampling of the drilled subsurface material for subsequent laboratory analyses. The maximal resolution of the A4-Tech PK-910H camera is $\sim 0.1 \mathrm{~mm}$, while the maximal resolution of the close-up imager (CLUPI) onboard ExoMars will ideally have about $0.01 \mathrm{~mm}$ spatial resolution. However, the real spatial resolution might be lower, and thus, our field tests provide a conservative approach as to what CLUPI will be able to identify.

The collected samples were analyzed in the laboratory at the home institute with a NICON Eclipse E600 POL microscope with a capability of $4 \times, 10 \times, 20 \times$, and $40 \times$ magnification. Further analyses with infrared (IR) and Raman spectroscopic methods, as well as particle morphological studies, are ongoing and will be detailed in future articles. Methodological results could be gained by comparing two types of images: Remote sensing images of Google Maps with 0.3 and $2.0 \mathrm{~m}$ spatial resolution, which are somewhat lower than the maximal resolution HiRISE images of the martian surface with $0.25 \mathrm{~m}$. The other type of images are on-site photos with resolution of $0.1-0.5 \mathrm{~m} / \mathrm{pixel}$, which is comparable to the $\mathrm{Pa}$ noramic Camera's (PanCam) resolution onboard EXM as recorded from several meters' distance.

\section{Results}

Field work was performed over the course of 5 days in the field along the Marrakech-Ouarzazate-Erfoud-ZagoraOuarzazate-Marrakech route $(850 \mathrm{~km})$ (Fig. 1). Image and sample acquisitions were acquired at 70 field stops, some of 


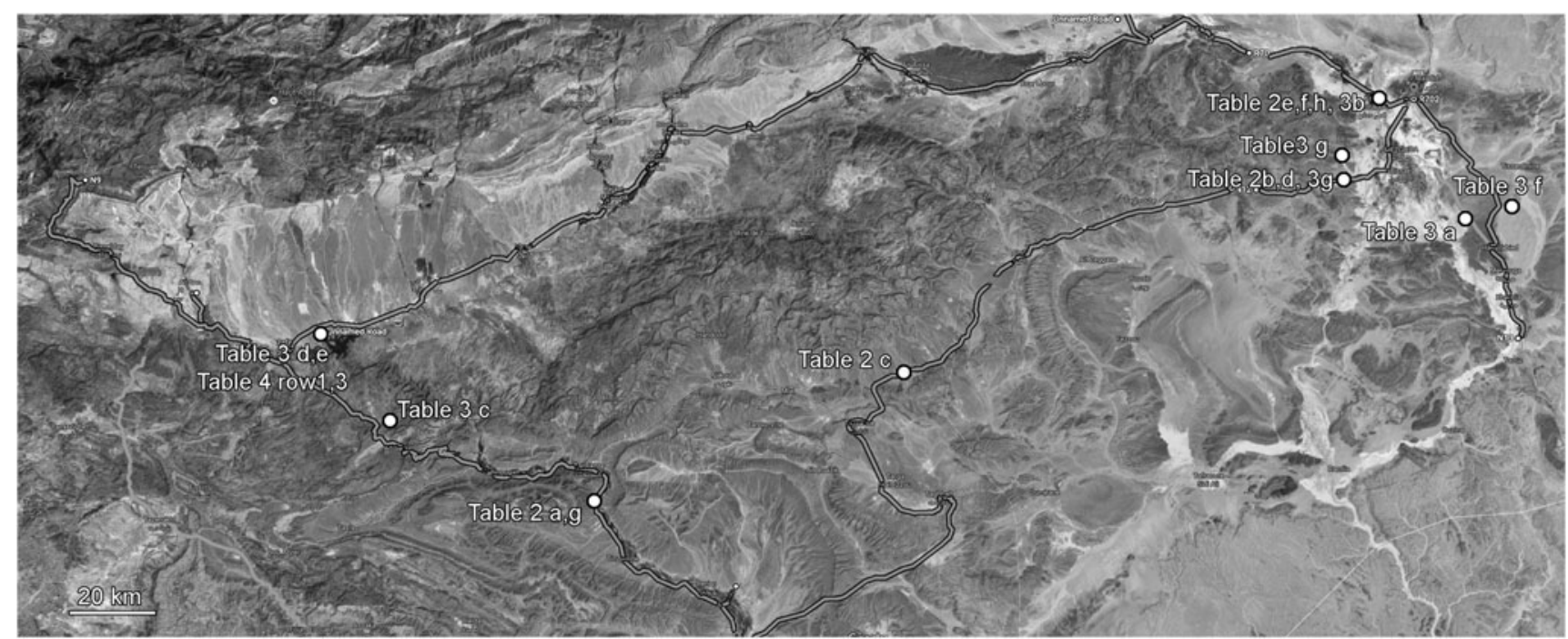

FIG. 1. The route of the expedition with the locations of those stops, which are also indicated in the tables of this article.

which were associated with drilling activities. Below, we have included an overview that focuses on how these analogue sites would be investigated so as to support planning for field work on Mars with a special emphasis on geological observations at different spatial scales. We also outline our overall findings and observations as they apply from larger to smaller spatial scales, that is, from satellite images to those acquired at the microscopic level.

\subsection{Comparison of remote sensing versus in situ observations}

Various surface features characteristic of desert landscapes (Garvin et al., 1981; Christensen, 1986; Golombek and Rapp, 1997; Levy et al., 2009) were recorded on-site as panoramic photos and were then compared with satellite images. The observed surface features were grouped in such a way as to reveal similarities and differences between the two image types to improve interpretations when using satellite images (such information is exclusively used for landing site selection on Mars; Bridges et al., 2003; Arvidson et al., 2008). We also sought to estimate how far we could extrapolate by using remotely visible structures below the spatial resolution of remote data. For example, how would the presence of structures below the spatial resolution be detected by using the remote data available. The analyzed surface features at the Ibn Battuta field sites were classified into groups termed cliffs $(<100 \mathrm{~m}$ diameter, isolated and elevated rock exposures), hills ( $>100 \mathrm{~m}$ diameter elevated structures), general rocky desert (reg) surfaces with scattered rock blocks and/or gravel, general sandy desert surfaces with sand dunes (ergs or sand seas), lakes, wadis, and transition zones between each characteristically different surface texture areas (Mabbutt 1977).

Characteristic image pairs of remote sensing-based and in situ recorded surface features are seen in Figure 2. By analyzing these images, the following features are visible (coordinates are given in brackets at the end of each subset caption below).

In Figure 2a, cliffs (1 in Fig. 2a) could only occasionally be identified in remote sensing images due to illumination geometry that casts shadows and thereby hinders recognition. Shadows might infer the existence of natural outcrops and could be used together with regional geological context to identify proper locations in vertical strata for on-site analysis. The joint use of remote sensing images and on-site photos helps to link the collected samples to regional-scale geological units $(31.430361 \mathrm{~N},-4.303556 \mathrm{~W}$; Google Maps coordinates).

In Figure $2 b$, illumination created brightness differences between dunes and their subunits ( 1 in Fig. $2 b$ ); dark surface gravel cover ( 2 in Fig. 2b) and bright underlying evaporites can be easily recognized in satellite images. Due to the dark gravel surface that overlies evaporites, however, the identification of stratigraphy required in situ field work. Spatial arrangement, including stripe-like features at the edges of the dark area, can roughly be identified in the satellite images $(31.193278 \mathrm{~N},-4.109361 \mathrm{~W})$, but the origin may be diverse and unidentifiable in remote sensing images only.

In Figure 2c, large, tilted bedrock layers are easily recognizable in this image due to their different albedos ( 1 and 2 in Fig. 2c). Although a sampling may seem to be identifiable with remote sensing data, the proper sampling point to be selected requires further analyses at higher resolution $(1-10 \mathrm{~m}$ scale) images $(31.008889 \mathrm{~N},-7.102444 \mathrm{~W})$.

In Figure 2d, steep edges ( 1 and 2 in Fig. 2d) of ephemeral river (wadi) banks form outcrops and can be spotted on images taken only under proper illumination conditions $(31.040806 \mathrm{~N}$, $-7.124944 \mathrm{~W})$.

In Figure 2e, linear dunes, barchans (1 and 2 in Fig. 2e), and sharp contact lines between dune sand and bedrock material are clearly visible on remote sensing images. These image pairs demonstrate that substantial albedo differences help to identify ideal locations for in situ work $(31.280222 \mathrm{~N}$, $-3.989361 \mathrm{~W})$.

In Figure 2f, sharp contact lines (1 in Fig. 2f) between dune fields; dune-free, deflation surfaces; and large star dunes ( 2 in Fig. 2f) can be recognized in this image $(31.211028 \mathrm{~N}$, $-3.999667 \mathrm{~W})$.

In Figure 2g, strong albedo differences are visible in these image pairs between dark basaltic rocks ( 1 in Fig. $2 \mathrm{~g}$ ) and 


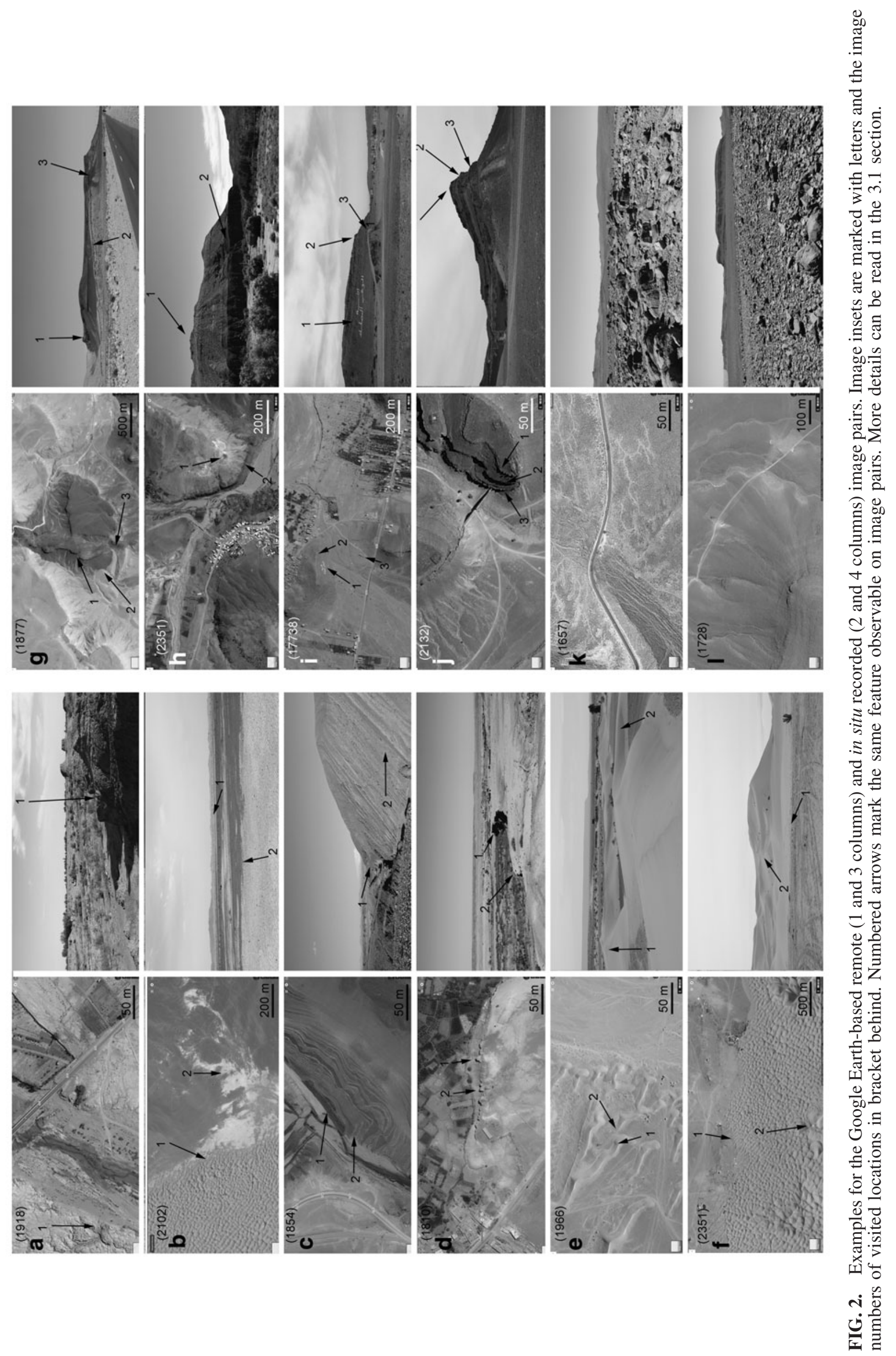


yellowish-reddish carbonates ( 2 in Fig. $2 \mathrm{~g}$ ), which are emphasized by mass wasting ( 3 in Fig. $2 \mathrm{~g}$ ) from local heights $(31.450167 \mathrm{~N},-5.665667 \mathrm{~W})$ and transport of the darker material onto the brighter carbonates.

In Figure 2h, outcrops of horizontal layers characterized by different albedos ( 1 in Fig. $2 \mathrm{~h}$ ) form a horizontally stratified hill (2 in Fig. 2h) (31.167472 N, -7.472917 W).

In Figure 2i, hills of different heights and slope exposure (1-3 in Fig. 2i) are present as barely observable structures in remote sensing images, demonstrating the importance of geometric conditions for satellite image acquisition $(31.547639 \mathrm{~N}$, $-4.881556 \mathrm{~W})$.

In Figure 2j, rock layers with their vertical outcrop walls and sharp edges (1-3 in Fig. $2 \mathrm{j}$ ) emerge in this photo and the identification is aided by shadow, useful for locating sites where the vertical strata could be analyzed $(31.297944 \mathrm{~N}$, $-4.402556 \mathrm{~W}$ ).

In Figure 2k, typical reg (specific desert type) surface with reddish clayey and iron oxide-coated material in between blocks $(30.748389 \mathrm{~N},-6.68625 \mathrm{~W})$.

In Figure 2l, typical reg surface differing from Figure 2k in boulder and gravel sizes and color, where ephemeral fluvial channels are obvious on satellite images $(30.780417 \mathrm{~N}$, $-6.661861 \mathrm{~W})$.

The analyzed terrain types at Ibn Battuta analogue fields were often sedimentary in origin, including old and recent ones, occasionally with ongoing fluvial and/or aeolian formation processes. As sedimentary successions and often water-related terrains will be targeted in future Mars missions (Doran et al., 1998; Peeters et al., 2009; Coradini and Orosei, 2011), we emphasize on the analysis of features of various sediment deposition mechanisms. Changes in the environmental parameters during deposition could directly be observed in the strata (thickness, lithology, mineralogy), which are obviously rarely seen in satellite images due to viewing geometry and limited spatial resolution. However, several sedimentary patterns/structures could be identified on satellite images, too.

Debris flows (talus slopes) can be observed in many pictures, both on the satellite and on-site images. The shape and exact size can be estimated by using satellite pictures for structures $>100 \mathrm{~m}$ in size, as the whole structure cannot be seen in the field. Their occurrence is indicative of erodible bedrock affected by mass wasting due to mainly mechanical weathering and erosion. In situ analysis could highlight the type of the mass wasted sediments, the thickness, grading, and sorting, and improve our understanding of the transport process.

Two basic types of deserts are present in Morocco among the Ibn Battuta sites: stone deserts and sandy deserts (regs and ergs). It is well known that the approximate size of large rock blocks can be discerned with the use of satellite images, while in situ images allow for determination of lithology sorting and dune size within sand features and varying sized gravel and pebbles. Based on a local in situ survey, the stone deserts show local diversity (rock type, pebble/gravel size, occurrence), and their satellite images reveal a diverse number of features. No connection, to date, has been made between the appearance of a given rock desert type in remote sensing data and appearance in in situ images, which might be an important topic for future research.
In some cases, dried lake beds can be identified in satellite images when aided by recognition of feeding channels and bright evaporites that were left behind after an active period. Nevertheless, sensing data acquired remotely have proven not to be sufficient for sure such identification. A smooth depositional area in remotely acquired images does not necessarily indicate a former lake bed. Images taken on-site, however, can provide further clues, in particular when the former lake bed is indiscernible due to cover such as (1) wind transported dust, (2) clay layers (without bright evaporites), or (3) rock fragments and gravels entrained by areal flash floods, leading to a dark surface appearance when viewed from above (see the example in Section 3.2.1 later). The sediment types (clay, evaporite, sand) and their relative location to each other in the Ibn Battuta region allowed for determination of the stratigraphy during in situ analysis and confirmation of the existence of former lakes. On Mars, former lake beds are often identified by their bank structures and feeding channels (Cabrol and Grin, 1999; Fassett and Head, 2008), but it should be noted that other lines of evidence will be needed for future missions to successfully identify lake bed features.

A comparison of in situ and satellite-based observations on different surface structures is summarized in Table 1, focusing on consequences for surface exploration.

Based on the general characteristics outlined in Table 1, satellite images support the identification of surface areas covered by the investigated structures, aid in route planning, support rough target identification and estimation of potential source regions of surface debris, and generally provide useful context for in situ work. By contrast, local images allow for constraining formation mechanisms, provide a record for temporal changes in the sedimentary environment, and aid in identification of compositional/ lithological characteristics of source regions. These considerations highlight the importance of acquiring local images of outcrops and surface structures before sampling, which, together with satellite images, would provide the proper context for interpretation of sample analysis results.

\subsection{The shallow subsurface zone}

During the Mars analogue field work in Morocco, we tested how the shallow subsurface exploration could contribute to understanding the formation of the region: especially what type of Mars-relevant information could be gained with a 10-30-cm-deep pit excavated at the analogue field. The rationale behind such activity is to support the understanding of the formation of a given area and get field experience that supports the planning of forthcoming missions. Few surface missions have had or will have such shallow subsurface exploration capabilities, such as the neutron spectrometer onboard Curiosity (Grotzinger et al., 2012) or WISDOM (Dorizon et al., 2016) and the driller (Di Iorio et al., 2012; Bost et al., 2015) onboard ExoMars. Experiences related to this topic are fairly limited, and here we provide some general geological and methodological lessons learned at Mars analogue sites.

Natural outcrops reveal subsurface zones, but these are not necessarily abundant, especially at smooth terrains filled with sedimentary material. Numerous outcrops are expected at impact craters (Hynek, 2004; Clark et al., 2005); however, 


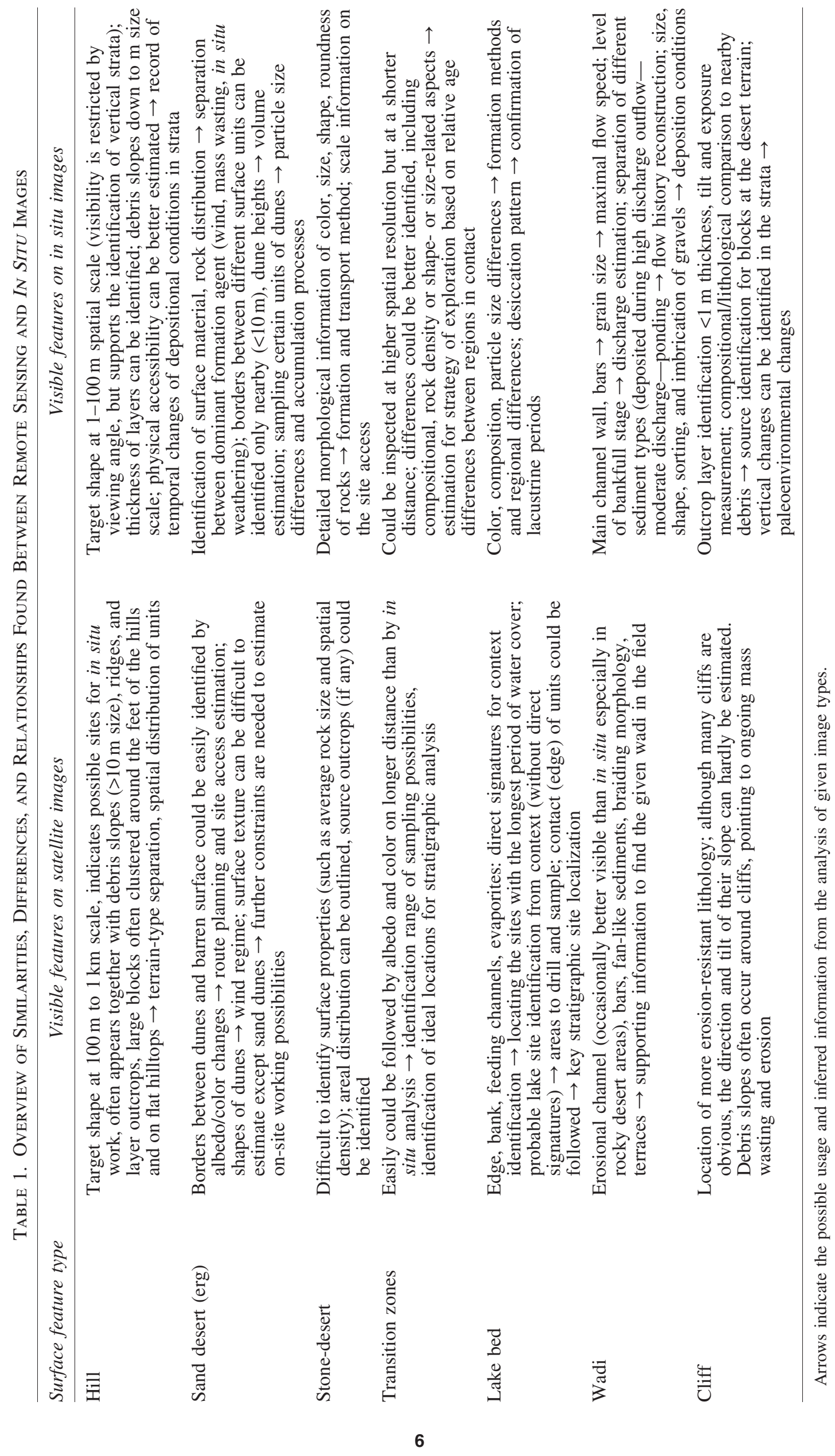


other types such as on fluvial terrains can also be important and were analyzed at analogue terrains. All the examples presented in this study are images of natural outcrops (Fig. 3 and Table 2) that were related to fluvial terrains (wadis). In such valleys, branches that formed recently incised older sediments and uncovered the top $0.5-1.0 \mathrm{~m}$ section of the subsurface zone.

By pure surveying of channel walls (similar to those in Fig. 3), the recent geological evolution history of the given fluvial terrain can roughly be estimated. This might have consequences on the planning of Mars exploration too, as the existence of outcrops requires relatively large, regionalscale surface structures that cut and expose subsurface features. Such large structures could be fluvial channels or tectonic faults at plains; however, hills could also expose their layers along steep walls. All the images in Figure 3 were recorded along 100-1000-m-long outcrops producing topographic undulations in branches, which formed at a
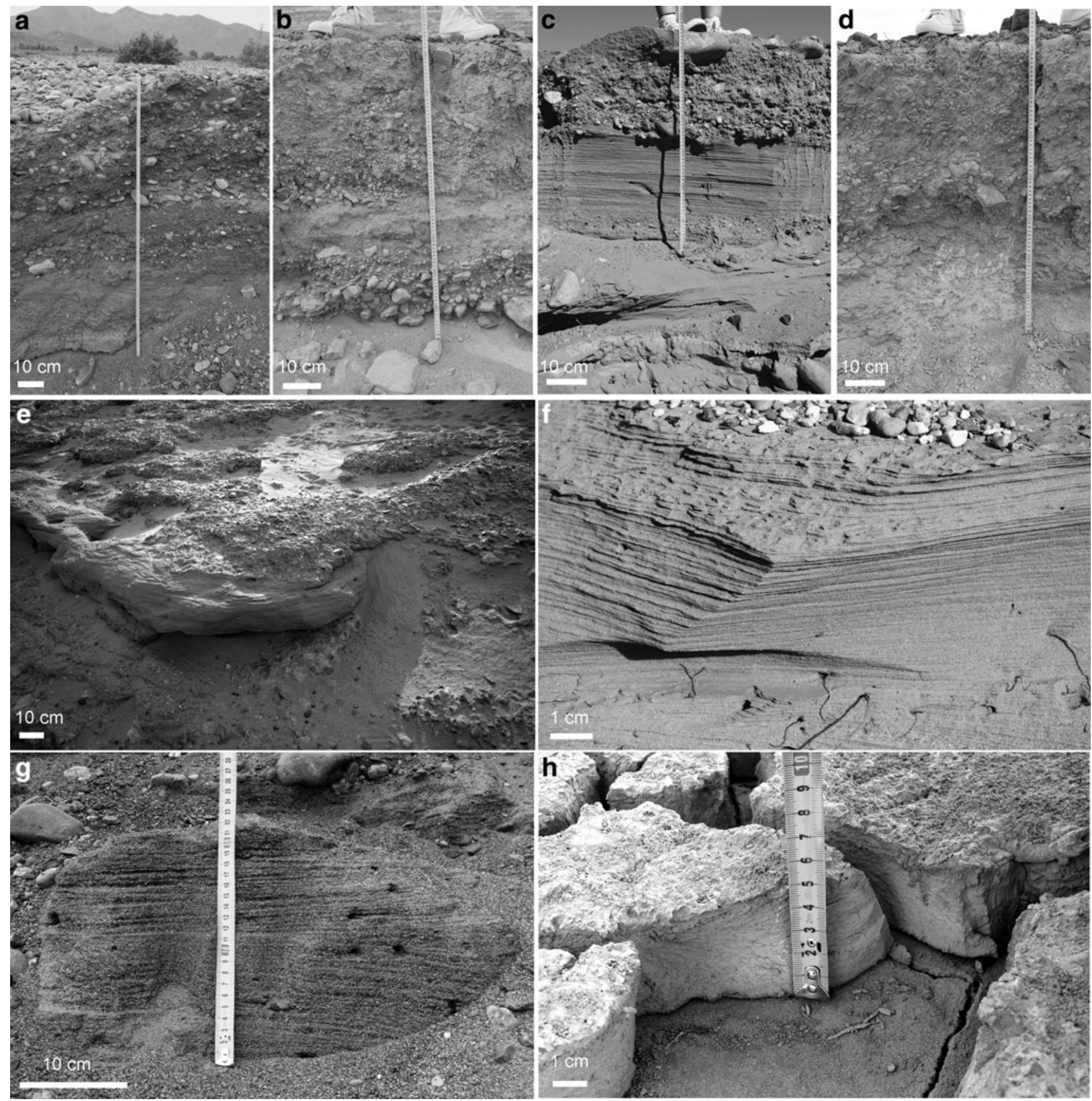

FIG. 3. Images of various fluvial processes related and by fluvial incut excavated natural outcrops. Periodic changes in deposited grain sizes (a-d), cemented gravel bar shielding the underlying deposits (e), fine laminated sand and aleurite size particles (f, g), desiccation produced laminated clays (h) could be seen on them. Most of the images show such fluvial stratigraphy, exhumed by later fluvial activities with deeper incut into earlier accumulated deposits. For specific details see Table 2 in Supporting Online Material. 
Table 2. Supported Online Material: General Information of the Natural Outcrops Indicated in Figure 3

\begin{tabular}{|c|c|c|}
\hline Image ID No. & Coordinate & General characteristics \\
\hline (a) (DSC_2271) & 30.620806 & Gravel layer contains small sand bodies. No grading or cross-bedding or \\
\hline Zagora area & -6.162806 & lamination can be observed. \\
\hline (b) (DSC 2143) & 31.300583 & Alternating sand and gravel layers. Grading can be observed in the form \\
\hline Erfoud area-Rissani 1 & -4.390778 & $\begin{array}{l}\text { of gravel layers. The pebbles' size is getting smaller upward, which } \\
\text { points to the decrease of the speed of the transporting fluid. }\end{array}$ \\
\hline (c) (DSC_2315) & 30.886389 & Consolidated gravel layer is on the top of sand layer. Periodicity cannot be \\
\hline Zagora area & -5.414722 & $\begin{array}{l}\text { observed in the gravel layer, however, its location on the top of sand } \\
\text { points to substantially increased discharge during its deposition. The } \\
\text { sand layer is flat sheet sand (at the middle of the image). }\end{array}$ \\
\hline (d) (DSC_2141) & 31.300583 & The gravel and sand mixed together in the upper section, suggestive of \\
\hline Erfoud area-Rissani 1 & -4.390778 & relatively hioh discharoe flow \\
\hline (e) (DSC_1942) & 361 & Well-cemented layers of sand and gravel. \\
\hline Erfoud area & -4.303556 & \\
\hline (f) (DSC_1937) & 31.430361 & The sand layer with well-bounded flat sheet morphology. Top of the section \\
\hline Erfoud area & -4.303556 & is noncemented gravel (by later short-lived water course). \\
\hline (g) (DSC_ 2274$)$ & 30.620806 & Unsorted and poorly cemented gravel layer without grading, what \\
\hline Zagora area & -6.162806 & $\begin{array}{l}\text { contains small sand bodies (the layered unit fills most of the image), } \\
\text { which show flat sheet morphology. }\end{array}$ \\
\hline (h) (DSC_1945) & 31.430361 & Polygon-shaped dried clay, strongly cemented sand and aleurite. Layering \\
\hline Erfoud area & -4.303556 & was produced probably by desiccation. \\
\hline
\end{tabular}

In the first column, the image identification number and the general name of the given terrain used by the Ibn Battuta Centre are written.

later period of the fluvial activity, and they cut into the former deposited fluvial sediment at the same site of the same river.

As natural outcrops are rarely present on smooth terrains, artificial outcrops were excavated by spade and hand forced drillings to expose the subsurface sedimentary layers (see Table 3 for locations). To identify the sites for drilling, local geological context and existing natural outcrops nearby (if any) were considered, targeting usually at the deepest locations of fluvial riverbed sample sites that experienced the longest and most recent periods of liquid water cover. For lacustrine environments, another approach was applied; locations close to the bank of ephemeral lakes were sampled to have a stratigraphic sequence that includes fresh evaporites at the top, other lake bed sediments, and the bedrock below to examine the whole stratigraphic sequence in its entirety thereby supporting comprehensive reconstructions of processes acting in this sedimentary environment

The excavation sites displayed in Figure 4 targeted fluvial locations with fine sand (Fig. 4b); cobbles/gravels (Fig. 4b) where the particles' size, layering, and imbrication could be easily analyzed. Former lakes (Fig. 4f) with sequences of sand, aleurite, and clay deposits were also analyzed; just like various rock desert types (Fig. 4a, c, e, g). Further details on these locations are found in Section 3.2.1 below.

3.2.1. Observing the shallow subsurface to identify the origin of rock debris. Based on some observations, even only a few cm deep subsurface excavations can provide such basic information that could not have been achieved otherwise by

Table 3. Locations and Main Characteristics of Shallow Subsurface Stratigraphy (Images Can Be Seen in Fig. 4)

\begin{tabular}{|c|c|c|c|}
\hline Image ID No. & Coordinate & Terrain type & Main observations \\
\hline (a) (DSC_2101) & $31.193278 \mathrm{~N}$ & Lake bed & Reddish dark siliceous gravels in various sizes $(1-10 \mathrm{~cm})$ \\
\hline Erfoud area & $4.109361 \mathrm{~W}$ & (dried up) & embedded in clay sediment. \\
\hline (b) (DSC_1940) & $31.430361 \mathrm{~N}$ & Wadi & Dry (upper $5 \mathrm{~cm}$ ) and wet sand in a wadi's riverbed. \\
\hline Erfoud area & $4.303556 \mathrm{~W}$ & & \\
\hline (c) (DSC_1755) & $30.780417 \mathrm{~N}$ & Stone desert & Black and reddish-brown, variable size $(1-50 \mathrm{~cm})$ gravels \\
\hline $\begin{array}{l}\text { Ouarzazate area-ADAD } \\
\text { (d) (DSC_1690) }\end{array}$ & $\begin{array}{r}6.661861 \mathrm{~W} \\
30.963583 \mathrm{~N}\end{array}$ & Wadi & $\begin{array}{l}\text { among fne sand. } \\
\text { Heterogeneous gravels (up to } 40 \mathrm{~cm} \text { ) mixed with wet fine }\end{array}$ \\
\hline Ouarzazate area & $6.817722 \mathrm{~W}$ & & sand. \\
\hline (e) (DSC_1715) & $30.963583 \mathrm{~N}$ & Wadi & Fine sand, wet around $0.5 \mathrm{~m}$ depth, mixed with \\
\hline Ouarzazate area & $6.817722 \mathrm{~W}$ & & heterogeneous (size, type) gravel. \\
\hline (f) (DSC_2038) & $31.211028 \mathrm{~N}$ & Lake bed & Cyclic strata of sand/aleurite and clay (at around 28 and \\
\hline Erfoud area-Chebbi & $3.999667 \mathrm{~W}$ & (dried up) & $42 \mathrm{~cm})$, sandwiched by wet sand. \\
\hline (g) (DSC_2156) & $31.300583 \mathrm{~N}$ & Lake bed & Clay and fine sand layers. \\
\hline Erfoud area-Rissani 1 & $4.390778 \mathrm{~W}$ & (dried up)? & \\
\hline
\end{tabular}



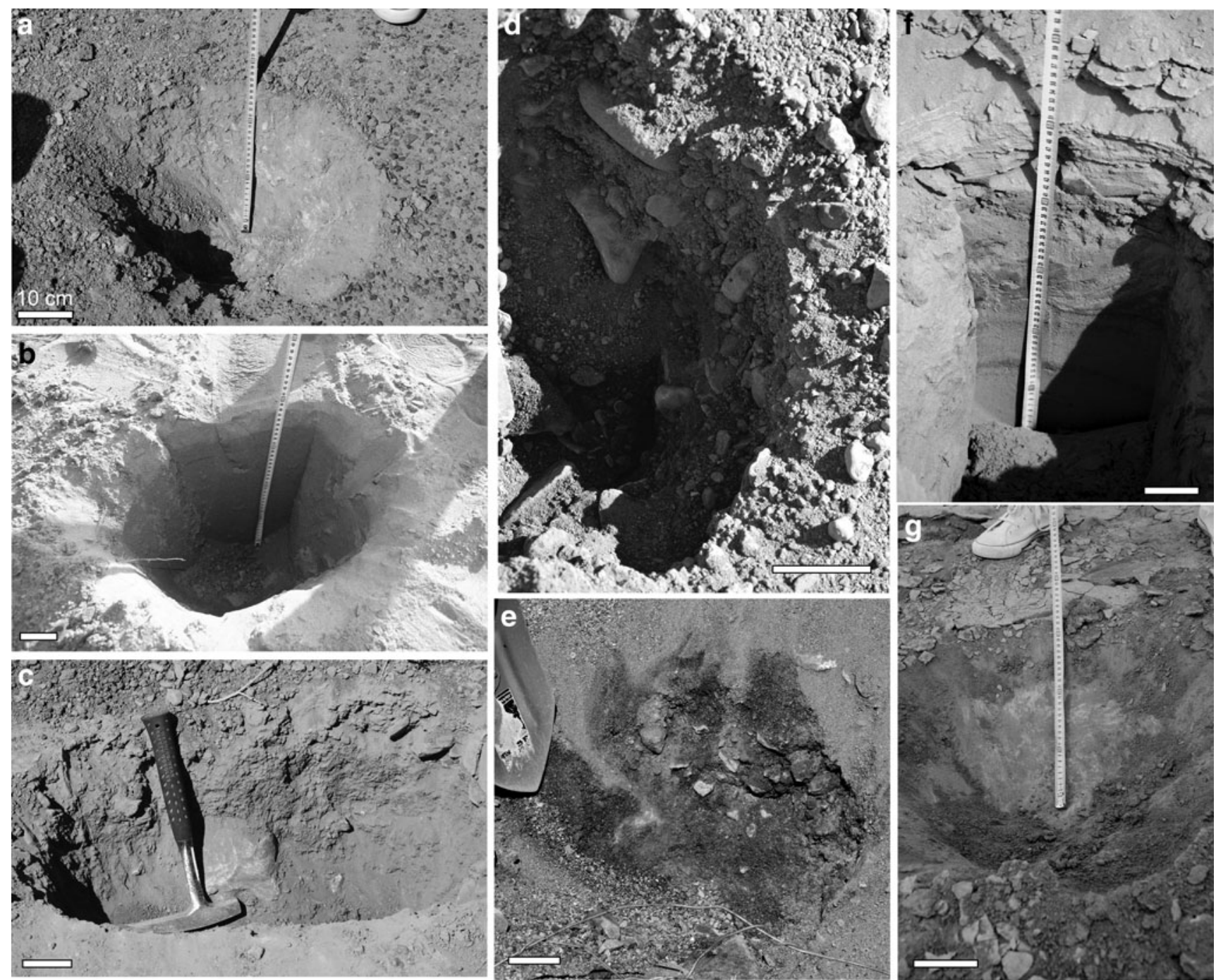

FIG. 4. Comparison of images of shallow subsurface exploration. The horizontal bars mark $10 \mathrm{~cm}$ length, relevant as scales around the middle of each image. More information on these locations can be found in Table 3 in the Image ID No. column.

using only remote sensing-based observations. In the following, such examples are presented, being of high importance to Mars, and they also allow for improving research methods for coming missions.

The site No. $0203(30.780417 \mathrm{~N}-6.661861 \mathrm{~W}$, Ouarzazate area-Adad) was a typical stony desert (reg type) with gravels/cobbles/boulders having different sizes (mostly 2$30 \mathrm{~cm}$ ) and shapes on the surface. (The terms "reg" or "serir" were originally used for stony desert surfaces covered by sheets of gravel) (Thomas, 2016.) The blocks were mostly angular/subangular, originated from the same type, and did not show any imbrication or other regularity in their spatial arrangement. Generally, it is hypothesized that these desert surfaces formed by a combination of aeolian activity (deflation vs. dust deposition) (Cooke et al., 1993; Wells et al., 1995) and in situ weathering from basement rock as the source material.

The 30-cm-deep excavation (Fig. 4a) revealed that there is no bedrock at this depth, which is what would have been expected for blocks produced by in situ weathering. Altogether, two trenches were deepened some meters away from each other into the subsurface (down to $30 \mathrm{~cm}$ depth and at least $40 \mathrm{~cm}$ width), but neither of these exposed the bedrock. The surface blocks varied in size between 1 and $25 \mathrm{~cm}$; some of them were relatively large and covered the surface almost homogeneously. The spatially homogeneous arrangement of gravels/cobbles and the lack of bedrock in the shallow subsurface led us to conclude that wind deflation and dust accretion, surface runoff, and/or lateral transport by creep (Cooke et al., 1993; Wells et al., 1995) are among those mechanisms shaping this landscape, while in situ weathering may safely be excluded.

The usefulness of simple shallow subsurface exploration is further demonstrated by another example, the homogeneous small particle debris field that remained at an ephemeral lake site after the active period (site No. 0403, coordinates 31.193278 N, -4.109361 W, Erfoud area) (Fig. 5). Here the surface debris resembles many other rocky desert surfaces: the terrain was covered by $1-2 \mathrm{~cm}$ diameter homogeneously distributed rectangular gravels. Some observations suggest that these grains were transported by areal floods; at the end of some small elongated depressions, these gravels were 


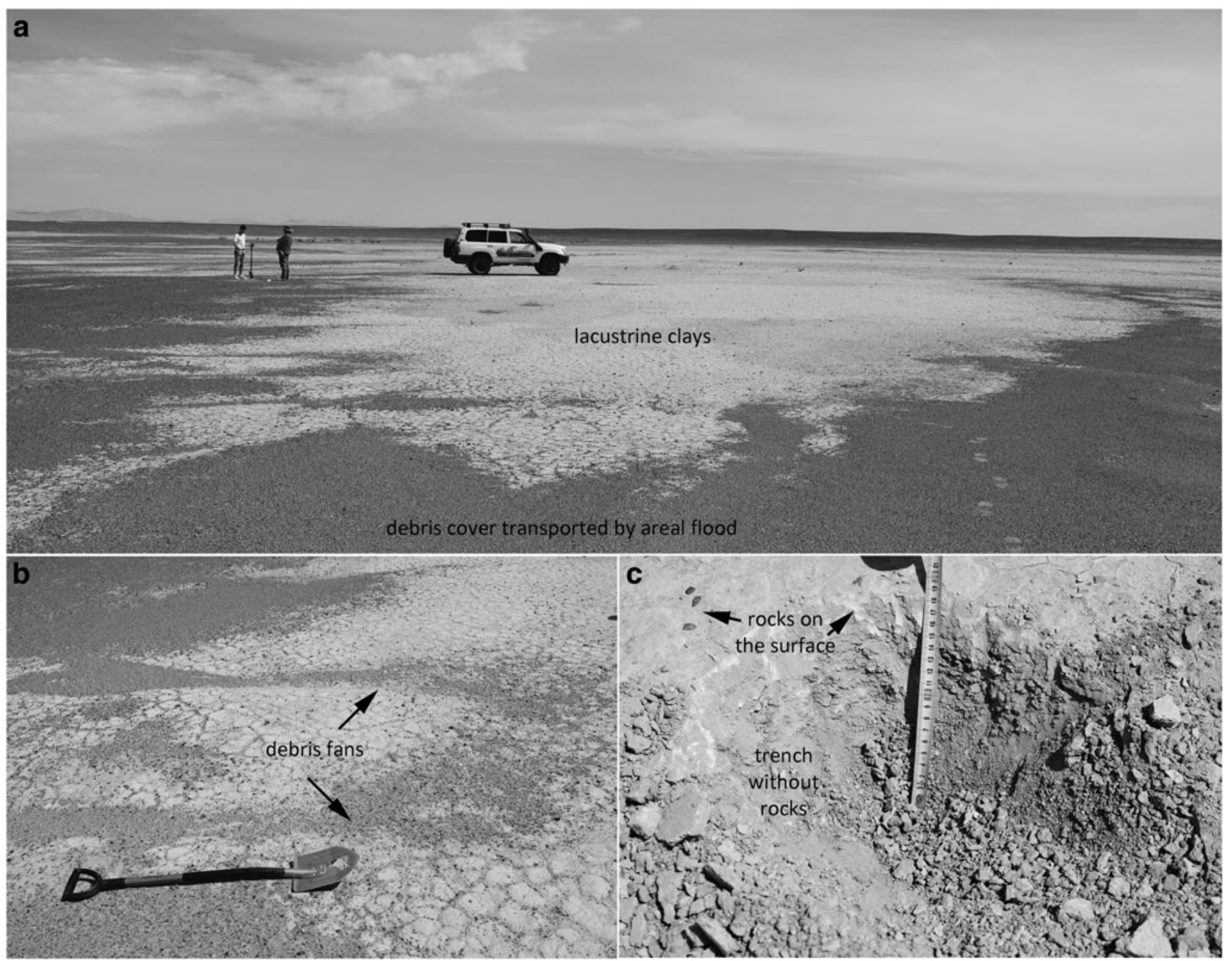

FIG. 5. Dry clay-covered lake bed (bright) (a) with subsequent flash flood-transported small dark rocky debris (b) at site No. 0403, with no rocks in the shallow subsurface (c).

accumulated in fan-like structures (Fig. 5b). Shallow subsurface excavation (Fig. 5c) demonstrated that the debris is present only on the surface, while below, at least down to $20 \mathrm{~cm}$ depth, only fine material composed of silt/clay exists. Thus, the rock debris was vertically unmixed with the aleurite-clay layer filling of the plain, but covered only the surface of the fine material, pointing to the sequence of accumulation events.

\subsection{Drilling and borehole-wall scanning}

Besides the inspection of natural or artificial outcrops, the shallow subsurface zone was explored by simple hand-

Table 4. Basic Parameters for the Four Sites Drilled During the Expedition

\begin{tabular}{|c|c|c|c|}
\hline Date (2016) & Site ID No. & Coordinates & General description \\
\hline September 16 & 02.02 & $\begin{array}{l}30^{\circ} 57^{\prime} 48.9^{\prime \prime} \\
6^{\circ} 49^{\prime} 03.8^{\prime \prime} \\
\text { Ouarzazate area }\end{array}$ & $\begin{array}{l}\text { Wadi, fine sand- }-0.4 \mathrm{~m} \text { blocks, vertical ( } \mathrm{dm} \text { scale) and horizontal } \\
\text { ( } 10 \mathrm{~m} \text { scale) heterogeneity (in particle size, shape, and rock type), } \\
\text { wet at } 0.5 \mathrm{~m} \text { depth. }\end{array}$ \\
\hline September 16 & 02.05 & $\begin{array}{l}31^{\circ} 02^{\prime} 31.7^{\prime \prime} \\
7^{\circ} 06^{\prime} 58.4^{\prime \prime} \\
\text { Ouarzazate area- } \\
\text { Ben Haddou }\end{array}$ & Heterogeneous distribution of particles in large stripes. \\
\hline September 17 & 03.02 & $\begin{array}{l}31^{\circ} 25^{\prime} 49.3^{\prime \prime} \\
4^{\circ} 18^{\prime} 12.8^{\prime \prime} \\
\text { Erfoud area }\end{array}$ & Bottom of a wide wadi, heterogeneous at $10 \mathrm{~m}$ horizontal distance scale. \\
\hline September 20 & 06.01 & $\begin{array}{l}30^{\circ} 59^{\prime} 2.6^{\prime \prime} \\
7^{\circ} 9^{\prime} 6.4^{\prime \prime}\end{array}$ & $\begin{array}{l}\text { Wadi, heterogeneous distribution (clay, fine gravel, bigger gravel), } \\
\text { latter layers: white, evaporite, and brown clay. }\end{array}$ \\
\hline
\end{tabular}


guided drilling (Table 4), accompanied with image acquisition of the borehole wall. More detailed analyses of the collected granular samples were planned to be performed in the laboratory of the home institute and this work is ongoing. The drilling activity was almost exclusively performed in wadis, where selection of a best site for sampling required a brief survey of exposed bank walls. Site selection always involved different spatial scales; it started with satellite image analyses at the landscape/landform scale (approximately $\left.10^{2}-10^{3} \mathrm{~m}\right)$, continued on-site at the local scale $\left(10^{0}-\right.$ $10^{1} \mathrm{~m}$ ), and finished at the scale of sedimentary features (approximately $10^{-1}-10^{-3} \mathrm{~m}$ ). An example sequence of analyzed scales by using this approach is presented in Figure 6 (drilling site 0601).

In Figure 6, both the context (satellite images) and on-site images are presented for the fourth drilling site at $30.983 \mathrm{~N}$, $7.151 \mathrm{~W}$. The investigated structure is a 400-600-m-wide branching wadi that can be seen in Figure $6 a$ and $b$. Figure $6 c-e$ displays a closer view of branches with different surface debris cover, including exposed fluvial sediments with gravel, sand, and aleurite-clay covers. Fluvial erosion resulted in natural outcrops, as floodwater cut into earlier deposited fluvial sediments, occasionally down to around $1 \mathrm{~m}$ depth. Topographic lows in channels produced during the last active fluvial episode were often filled with desiccated clay-evaporite layers and/or wind-driven sand accumulations. The fluvial and wind-driven fine material can be differentiated from ca 10-20 m distance on-site; a similar situation may be expected on Mars in exposed surface fluvial channels, and thus, a closer on-site inspection could be useful there.

Natural outcrops with fluvial sedimentary sequences can be seen in Figure 6h. Differences in bedding and grain size along the strata could be observed by inspection (from $\mathrm{m}$ to $\mathrm{dm}$ distances), which, although a trivial matter on Earth, would require time and effort to conduct a survey along outcrops during Mars exploration. This has been done a number of times with recent Mars missions; however, no sophisticated methodology has been developed as to how to conduct these surveys and optimize the number of nearby outcrops to visit. This context generation task could also be greatly improved by the use of drones (Singer, 2012; Svendsen et al., 2013). Based on the field experiences, the layering structure, the existence of agglomerates, the occurrence of larger grains could be enhanced by wind-driven selective erosion, and thus, such small-scale features could be easy to identify from open-air outcrops.

Using borehole-wall scanning in the drilled hole (Fig. 6g), images were acquired (Fig. 6i1-i5). While the contour of each particle could occasionally be blurred, individual grains above $0.2 \mathrm{~mm}$ diameter could firmly be identified. It is clearly visible that the larger grains are not rounded. The grain surfaces look smooth, but this observation may be affected by the quality of pictures as these features are around the limit of spatial resolution. No structure or regularity can be seen in these borehole-wall images, despite the fact that layering was observed on the same sedimentary strata exposed at a nearby outcrop. However, it is worth mentioning here that particle size and the level of cementation were the main differences between the different layers, as opposed to albedo or color. This implies that layering might be difficult to observe inside drilled boreholes on Mars.
The samples seem to be relatively well sorted (no more than two dominant particle size ranges are present: fine sand and aleurite), except those in the Figure 6i3 and i4. In these two cases, larger grains ( $>1 \mathrm{~mm}$ diameter) appear, and thus, these stratigraphic levels are less well sorted than the others, probably referring to higher energy transport conditions. Aggregates cannot be identified (they are present, however; see next paragraph), and the layering is almost invisible in the borehole-wall scanning compared with the outcrop wall.

The shape of the grains is similar in all samples acquired along the vertical strata; they are usually angular without sharp edges. In samples collected at 30 and $40 \mathrm{~cm}$ depths and close to the surface, the finest grains often stick to bigger grains to form aggregates. The aggregates from shallow $(1 \mathrm{~cm})$ depths are often cemented by evaporate minerals and clays that formed during the final stage of the wet period.

Higher quality laboratory images (Fig. 7) improved the information gained on particles. It is of note that images with similar resolution will be taken by the CLUPI camera onboard the EXM rover. Differences in image quality between the images taken on-site and those recorded under ideal lighting and geometric conditions in the laboratory are displayed in Figure 7, highlighting the importance of image acquisition conditions. This observation may have a methodological aspect for Mars exploration; quality of images to be recorded by CLUPI will likely be lower than determined during laboratory testing by MicrOmega $(20 \times 20 \mu \mathrm{m})$.

The better quality of laboratory images resulted in improved size and shape determinations in the smaller size range (especially $<0.2 \mathrm{~mm}$ ), and more details of the grain surface patterns became visible. Among the minerals present, quartz, carbonate, mica, Fe-minerals, and some salt could be identified. The grains are more visible in the laboratory pictures, not just because of the better viewing geometry but also because fewer aggregates were present as they fell apart during sampling and transport. Besides, aggregates were hardly visible while embedded in the sediment matrix at their original location (wall scanning), but could be easily identified once the samples were collected and weakly pulverized due to simple transport. These aggregates were loose and easily fragmented, and the cement proved to be a mixture of iron oxides and clays.

The difference in characteristic grain size between samples collected at various depths along the vertical sampling column could be easily seen both in the field and in the laboratory. Smaller particle size in the upper samples (Fig. 7A and B) (range: 100-200 $\mu \mathrm{m}$ ) and larger for the underlying horizons (Fig. 7C and D layers) (range: 800$1500 \mu \mathrm{m}$ ) imply decreasing sediment carrying capacity of a gradually weakened flow. The layer characterized by larger grain size may allow for estimation as to which sediments were laid down during elevated discharge. However, this analysis includes the data obtained in vertical strata of only one drilling. Open air natural outcrops offer a better overview at more locations, however, and their analysis may allow a spatially better identification of the sediment layer associated with the peak discharge at a given area.

Evaporites and clays appear as cements between grains in Figure $7 \mathrm{f}$ and $\mathrm{g}$ insets. These samples provided many 


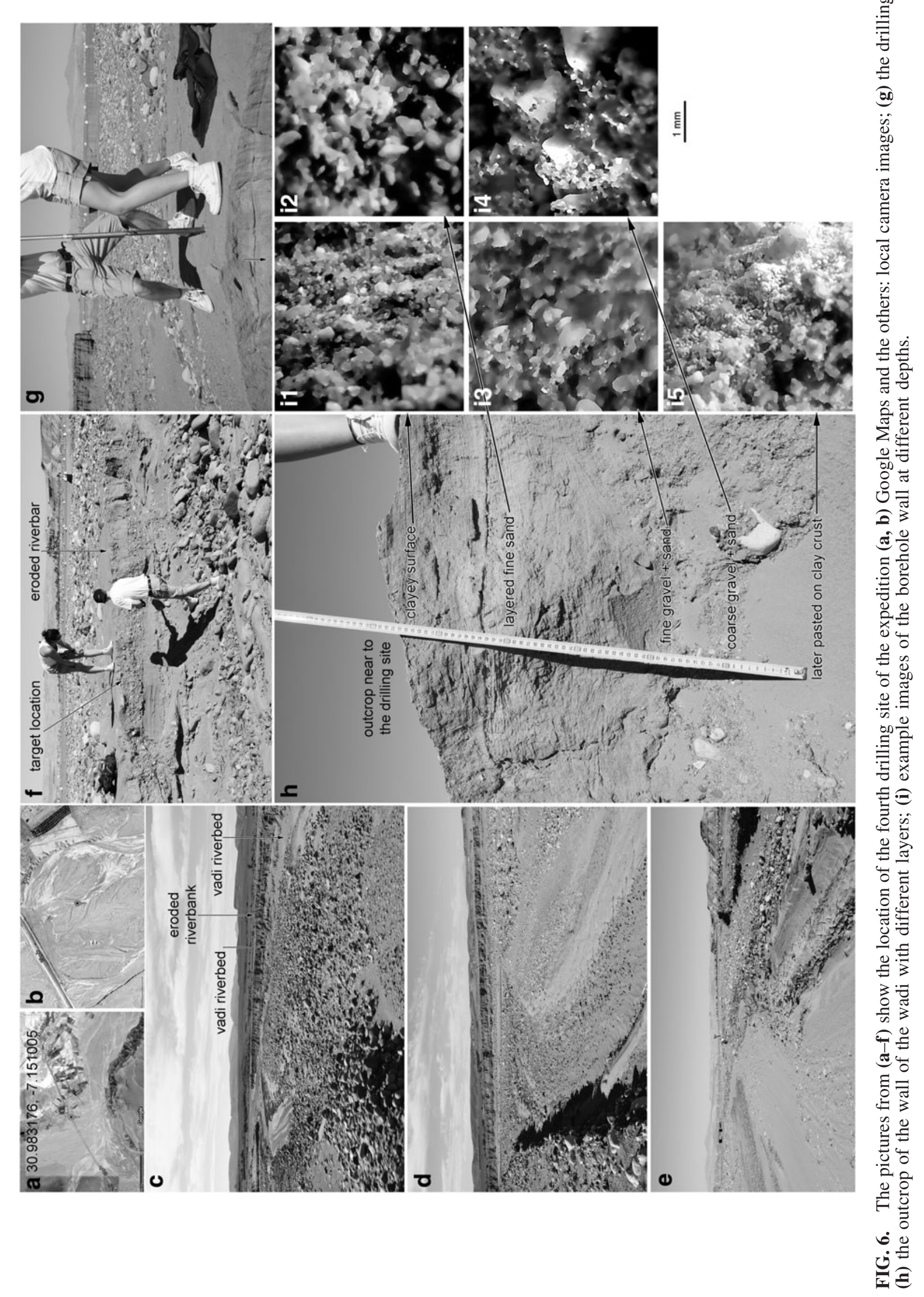




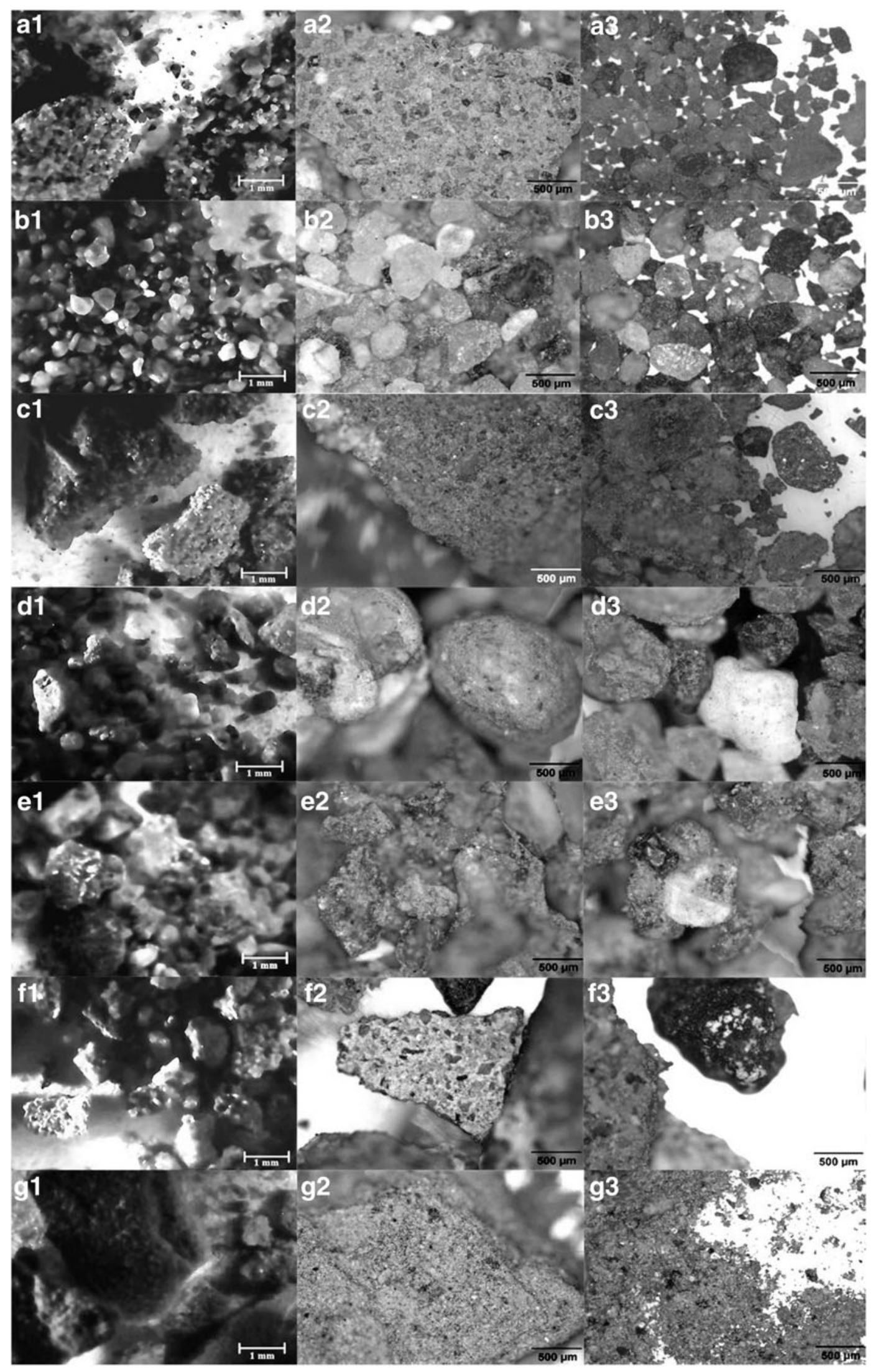

FIG. 7. Samples from $1,4,10,30$, and $40 \mathrm{~cm}$ depth (from the top row to the bottom, respectively). The last two rows show fragments (as agglomerates) of the evaporite and subsequently formed clay crust. The photos in the first column were made by A4-Tech PK-910H web camera. The pictures of second and third columns were made by NICON Eclipse E600 POL microscope in the laboratory. For the detailed explanation on the inset images see the description on section 3.3. 


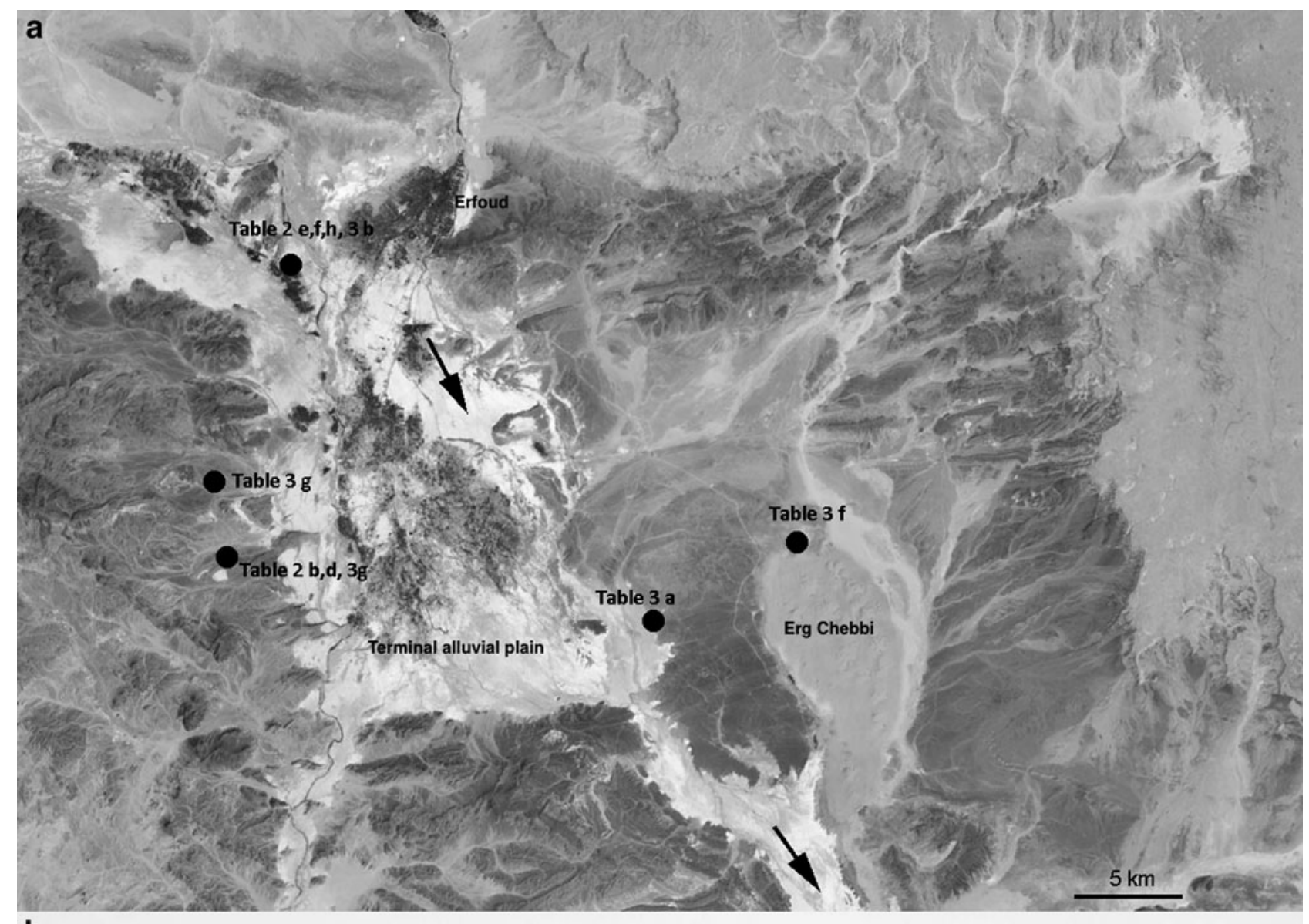

b

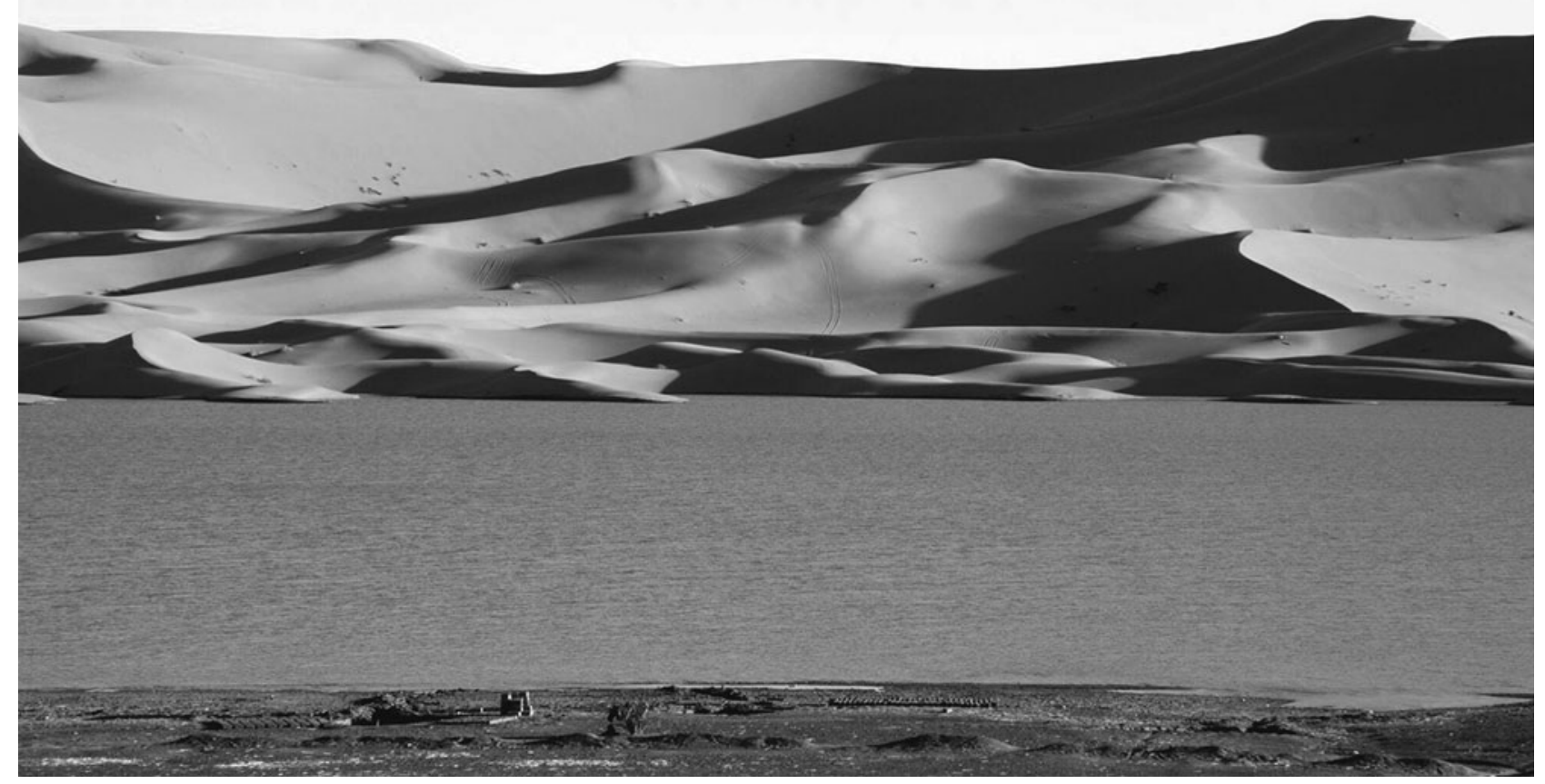

FIG. 8. The depositional areas of Oued Ziz (flow direction according to arrows) marked by the bright terrains in the middle (a). Wintertime ephemeral lake produced by rain provided discharge at the alluvial plain (b). 
aggregates, and grains were attached stronger to each other than in other sampled layers. These cements may have formed after the termination of fluvial activity, during the desiccation phase when little liquid remained and finally evaporated.

\section{Discussion}

The major focus of this work is on the discussion of methodological issues relevant to the ExoMars mission as opposed to the sedimentary/facies interpretations. Therefore, in this section, the major findings are grouped into three topics, from the largest to the smallest spatial scales, and focus on their relationships to provide examples as to how the growing knowledge of information from different spatial scales can be connected to support the targeting of sampling. These include (1) the relationship between observations at different spatial scales ( $\mathrm{m}$ to $\mathrm{km}$ domain) to see what type of surface features are expected on Mars beyond the limit of resolution of orbiter images and how this information could influence the planning of in situ sampling work), (2) the type of results that may arise from the analysis of $\mathrm{cm}-\mathrm{mm}$ scale observations during the shallow subsurface exploration using field analogues related to former liquid water, and (3) results gained from the $\mathrm{mm}-\mu \mathrm{m}$ scale observations of outcrops and drilled samples.

Regarding the comparison of satellite-based and on-site panoramic images, those features were separated that could, or could not, be observed on the remote sensing or in situ images. While remote sensing data effectively support the identification of sites characterized by large albedo differences and/or sharp borderlines between various landforms, the appearance (and identification) of various slopes and vertical channels or exposed rock walls strongly depends on slope exposure and illumination angle. This points to the importance of acquiring several images from the same important target site for Mars under different illumination and geometric conditions. This is somewhat in contrast to current attempts, during which image acquisition is done by orbiters with an almost vertical viewing angle and under the same illumination conditions for repeated imaging of the whole planet. The creation of high-resolution Digital Terrain Models (DTMs) also provides useful information in this context. On top of the deviations, due to different spatial scales, our survey confirmed the better identification and characterization of vertical sequence of layers (including thickness and inclination angle of certain layers) using in situ images, and the importance of target identification using satellite images.

It is less well known that various types of rocky deserts with different surface scenes imaged by in situ work also show different appearances when viewing from above (especially in albedo and color), but no extrapolation to the surface desert morphology is possible when using only satellite images. However, the search for correlations between large-scale (satellite based) and small/local-scale appearance of rocky deserts is a promising topic. Such surveys could be ideally made at the Ibn Battuta analogue locations in the future, as several different rocky desert types are found there. The findings may have an impact on Mars exploration, as it may lead to a better understanding of active desert forming processes on the red planet.

Recently formed rock cover also tends to hide the surface below. Based on a field survey at an ephemeral lake site
(No. 0403), homogeneous surface cover of small rocks with moderate spatial density (ca dozens of 1-2-cm-sized rock fragments per $\mathrm{m}^{2}$ ) is capable of masking the bright evaporiticclayey surface layers as viewed from above. Thus, the identification of the ephemeral lake is hampered.

The fluvial context (location of various branches and identified flow direction) could be easily determined with satellite images, supporting the selection of target areas for in situ analysis of fluvial processes at $100 \mathrm{~m}$ spatial scale. However, site localization for the most relevant sampling point requires on-site analysis, as the sampling sites show substantial differences in the period and characteristics of water cover and so on, at $1-10 \mathrm{~m}$ spatial scales. The field surveys revealed that $10-100 \mathrm{~m}$ long local natural outcrops with exposed subsurface layering are present along many wadis on Earth. Similar features have not been identified on Mars to date. Their $1 \mathrm{~m}$ or smaller vertical undulation is difficult to observe when using currently available data sets; however, they might be abundant and could support the ideal sampling site localization.

\subsection{Shallow subsurface exploration}

Shallow subsurface exploration resulted in further information with regard to the geological history of the given location that could not have been identified from remote sensing images or data collected at the surface on-site. Analysis of the top $20-30 \mathrm{~cm}$ shallow subsurface zone provided insight into the origin of the surface debris, as shown by some examples discussed in the points below.

- Ephemeral lakes leave few observable surface features such as banks or feeding channels, probably because of their short lifetime, shallow depth, subsurface inflow, and the fact that they are fed by sheet wash. Markers of ephemeral lakes on the surface may include polygonized fracture systems, and sometimes no more than the plain horizontal level is the major sign. At site No. 2038, the 40-cm-deep subsurface excavation exposed two cycles of lacustrine evolution: sand-sized grains covered by clay layers on the top; this setting was repeated twice. Such shallow excavations may allow for clarifying water-related issues on Mars too, especially to confirm the existence of former lakes.

- Ephemeral areal wash could scatter small (cm sized) rock fragments almost homogeneously on the surface with only a few signatures that point to the transport method, and thus, the terrain might look similar to many other rock desert scenes. At site No. 0403, after the lacustrine period of sedimentation, areal flow transported $\mathrm{cm}$-sized rock fragments. A few surface signatures pointed to this transport method, such as the accumulation of grains at small depressions. Further information acquired during shallow subsurface excavation with regard to the lack of similar rocks at dm depth inside the shallow clay-evaporite layer is compatible with the idea that these blocks were surface transported during a wet period (probably by areal wash), after the clay forming lacustrine one. (This location type differs from the below-mentioned reg-type site in that here only smallsized grains were transported by areal wash, while at the reg-type site, blocks were much larger and the whole system was located at a sloping area.) 
- The formation of rock blocks covering desert surfaces might suggest in situ weathering, such as is the case at the reg (serir)-type site (No. 0203 visited locations). The wide size distribution (from $1 \mathrm{~cm}$ up to $30-40 \mathrm{~cm}$ diameter) of blocks and their homogeneous spatial distribution without any accumulation or imbrication signature indicate that these blocks were not transported here (neither by mass wasting or water flow) and that they probably formed by in situ weathering. However, shallow subsurface exploration showed that there is no bedrock to weather, that is, down to $40 \mathrm{~cm}$ depth. Based on the literature (Parsons and Abrahams, 1984; Svintsov, 2009; Durand and Bourquin, 2013), such reg-type sites form by in situ weathering and fragmentation of bedrock along with deflation of finegrained products. However, this is not probable here as the bedrock was missing, and thus, in situ weathering could have contributed only in an unusual way (the mixed emergence of other formation methods might contribute and the very long timescale of formation also could make the formation process and the explanation unusual). This case is an example of how shallow excavation can help to exclude a process that might look like a probable formation method by surface-based analysis only.

\subsection{Results of sub-mm-scale analysis}

The smallest scale particle and layer analysis (around the mm regime) were achieved by way of two methods: (1) an optical borehole-wall scanner and (2) later laboratory analysis at the home institute. A comparison of the two methods reveals the advantages and disadvantages of each, including the more difficult particle size estimation for the smaller grains and the lack of information on particle surface texture when using in situ (nonideal) observing conditions relative to those in the laboratory. (It should be noted that such differences strongly depend on particular detectors that were used, but tests with such instrument are crucial and point to possible future usage of high-resolution optical images of deposited particles on Mars.)

Based on the moderately wide particle size distribution at two layers (especially in Fig. 6i4), the action of water could be identified as a more probable agent than wind transport (when more narrow grain size distribution and lack of larger grains are characteristic) (Nichols, 2009) and mass wasting (when wider grain size distribution with large and extremely irregular shaped grains is characteristic) (Blum et al., 2005). Other than size, the shape of grains can also be roughly estimated by in situ images that support the identification of the transport method; however, the quality might not be enough to separate theoretical end cases of wind-transported, wellrounded, and fluvial transported poorly rounded grains for the sand fraction.

Aggregates are important components of many samples, which can inform with regard to aggregation processes before or during deposition (with Mars-relevant processes such as wet surface adhesion or duricrust formation), but these could be identified only under certain conditions. Agglomerates could be identified in the acquired and weakly pulverized sedimentary samples (during the later laboratory analysis) and not in the borehole-wall or in the outcrop surfaces observed during in situ work. However, it should be noted that the effective mechanical pulverization by the crushing station of ExoMars rover could also destroy such aggregates. Their identification could ideally be determined after sample acquisition and before pulverization, as recorded by the CLUPI camera.

\subsection{Connections between different spatial scales and the use of Earth analogues}

Based on the past decades of Mars surface exploration, in situ work has been targeted primarily with the use of remote images and landing site selection processes. For local work, "real-time" selection should be applied to identify and select ideal locations at meter and centimeter scales. This trend (focusing on on-site recorded images in target selection) has become more important for future Mars sample return mission (O'Neil and Cazaux, 2000; Sephton et al., 2013). Analogue work provides example methods and experiences as to how to target ideal locations by using various scales of data collectively (Table 5). Here, Ibn Battuta Centre's field sites could provide a specific contribution with regard to spatial scales, timescales, and hydrological systems as described below.

During the Mars exploration in recent decades, target types shifted from larger toward smaller spatial scales, visible in the 1-4 columns of Table 5, given that targeting of missions has become more accurate with our improved ability to land at smaller ellipses. Thus, analogue work should follow this trend, as it provides a test bed with which to improve methods as to how geological information of different spatial scales can be used to fine-tune the location of sampling sites. Here, the joint usage of satellite and in situ images could be improved by analogue studies specifically at Ibn Battuta Centre's field sites, including the extrapolation to rocky desert types from remote images and identification of probable fluvial incut produced outcrops. Another important aspect of Earth-based desert analogue sites has to do with the low speed of surface modification and the long duration of evaluated periods. Environmental conditions for deserts on Earth generally take longer to change than approximately $10^{1}-10^{2}$ years, and surface modifications are influenced substantially by climatic changes (order of $10^{5}-10^{6}$ years). In this aspect, the region where Ibn Battuta Centre sites are located suffered important changes since the Miocene (see details in an accompanied article by Ori in this special issue).

The large number of different analogue desert sites at the Atlas region that are close to each other provide the opportunity for easy logistical access and the development of future Mars missions' methodology, that is, how to consider and use regional and local context to identify the most waterrelevant samples for astrobiology. Based on the present scientific view, older locations have been of primary importance with regard to astrobiological studies on Mars; however, young and even recent features at Ibn Battuta sites could help to develop new methodologies for the analysis of very slow surface modification of many old martian surface structures that can be remarkably intact even at the present.

The small-scale in situ analyzed features and related shallow subsurface characteristics of regional hydrological systems have widespread Mars relevance, which include 
highly changeable discharge, gradually diminishing water at the lower reach, evaporite and clay-rich deposits, and ephemeral standing water bodies. The investigated desert areas are dominated by ephemeral streams that flow southward from the Atlas Mountains, which are active only during rainy periods in the mountains. The most important of these rivers is Oued Ziz, its source located in the High Atlas Mountains, which flows though the Tafilalt region where a great deal of field work has been carried out. In the Tafilalt plain, the Oued forms alluvial plains rich in clay and evaporite deposits. In this area, the river loses much of its water such that it ceases to exist at the border of Sahara. In the mountain reach, the discharge is close to $1000 \mathrm{~m}^{3} / \mathrm{s}$ in winter and does not exceed $10 \mathrm{~m}^{3} / \mathrm{s}$ in summer.

In the investigated area, the Oued $\mathrm{Ziz}$ is strongly ephemeral, and it forms a set of terminal sabkhas (salty flats formed by evaporation in arid regions) (Hugget, 2007) made up of extensive clay, fine-grained sand, and evaporitic strata at the alluvial plains that accumulate during flooding. A portion of this water evaporates, but some of it typically recharges the shallow water aquifer. The water table is at a depth that ranges from 10 to $30 \mathrm{~m}$. The area of these terminal plains is about $20 \mathrm{~km}$ wide and $60 \mathrm{~km}$ long. However, the Oued Ziz represents a major river system in the Quaternary evolution of Sahara. During humid climatic periods, when Sahara was predominantly a savanna rich in lakes and rivers, Oued Ziz flowed from the High Atlas up to the Erg Inguid in Algeria, a distance of about $600 \mathrm{~km}$. Therefore, this major river is now composed of several independent reaches that are active locally depending on local and rare episodes of precipitation.

In winter, the water table can rise up to the surface in a few locations in the area of Erfoud (Figure 8). This area corresponds to two different systems: the sebkhas (ephemeral standing bodies of water on the order of $1 \mathrm{~km}$ wide, linked to the alluvial plain) and the border of the Erg Chebbi. This latter lake is the product of an aquifer that lies between the base of the sand of the Erg Chebbi and the substratum that consists of Paleozoic rocks. This aquifer is likely charged by rain that falls over the erg and penetrates to highly porous eolian sand of the erg. The lake lasts 2-3 winter months and disappears in the spring due to the decrease of rainfall as is the case for the sebkhas-type lakes. However, apparently the deposits are not composed of evaporites but of fine-grained clastic sediments. The site No. 2038 (mentioned above as ephemeral lake in 4.1 section) comprises such clay-like deposits and plain-shaped sediment accumulations without inflow-related channels.

\subsection{Applying the analogue results for Mars}

Several recent observations suggest the range of spatial scales (from orbital image scale to $\mathrm{cm}-\mathrm{mm}$ scale in certain outcrops) that should be used in forthcoming missions, including the planned Mars sample return, where highly targeted sampling is planned, partly from the subsurface. Researchers were able to effectively connect orbital data and in situ observations by the highly mobile Curiosity rover, in this case in situ results helping to extrapolate beyond the rover's traverse (Milliken, 2015). At the foundation of Mount Sharp in Gale crater, the border between thin and cross-bedding layers was observed by the Curiosity rover at a site within Gale crater, the location of which could not be 
determined from orbital data alone, but required in situ imaging from a meter-scale distance (Grotzinger et al., 2015). Curiosity also analyzed the Shaler outcrop (fluvial sand body) of only $0.7 \mathrm{~m}$ thickness with seven separate facies based on grains and bedding along the feature (Edgar et al., 2014). The Opportunity rover also demonstrated the importance of centimeter-scale analysis of outcrops in attempts to reconstruct past conditions by using scale cross-lamination observed from a decameter distance in Erebus crater, Olympia outcrop (Grotzinger et al., 2006).

However, there are few case study examples on the ideal number and spatial setting necessary to establish in situ observations supported by "high-resolution" geological context to facilitate centimeter-scale sample targeting. With the many lessons learned from analogue field tests kept in mind, future methodological needs for effective sample collection on Mars will need to be determined. A sequence of steps toward realization of these goals (observations at different levels) are summarized in Table 6.

The results gained by the analysis of the two main research questions noted here could support the targeting of forthcoming missions by the following topics (especially the knowledge gaps listed in the rightmost column in Table 6).

The acquisition of several orbital images of a same target area under different geometries should be tested, which would be quite difficult and expensive.

Early tests with drones would help to clarify the range of ideal and required observation types. It would also be useful to initiate a discussion with mission experts to discern how this suggestion would fit with the possibilities and capabilities of a regular orbiter mapping mission.

For the determination of the ideal numbers and spatial arrangement of outcrops required to be imaged nearby on the surface for firm geological context, establishment should be tested at analogue key sites.

The last level of targeting: the selection of a given layer or number of layers to be sampled should also be tested at analogue locations with sample acquisition from more locations than foreseen to select the most relevant ones consistent with the above acquired context. The possibility of more sampling and subsequent later analysis, including better laboratory facilities on Earth than are available onboard a rover, makes analogues ideal to develop and improve the method that should be followed during the Mars sample return.

\section{Conclusion}

In this work, we have presented an overview with examples and lessons learned during analogue studies conducted at Ibn Battuta field sites with the intent to discern how geological information from different spatial scales can be used to identify the best locations for targeted sampling. The remote images and local walking field survey-based analysis were completed by shallow subsurface exploration.

Comparing satellite-based and in situ recorded images, we were able to examine new ways by which to extrapolate key information from satellite images below the limit of spatial resolution. The identification of various rocky desert types (which differ in albedo and color when imaged from above) can be made in satellite images, but no guidelines are 
available to date as to how to use this variability to extrapolate differences in surface desert morphology and formation. Targeting for in situ work with the use of remote sensing data can be most effective if several images of the same target can be recorded under different illumination and geometric conditions (e.g., different local solar time), which would make remote images more informative. Analogue site study results suggest that it is not necessarily a requirement that ephemeral lake beds exhibit indicative surface features in every case, and occasionally only shallow subsurface exploration can indicate origin. Based on the analysis of wadis, a large number of horizontally elongated surface outcrops were exhumed by fluvial cut into earlier deposited sediments. Such outcrops can greatly support the location of the ideal target for sampling, but to date this has been minimally explored or applied to the study of Mars.

In this study, we found that stratigraphic features (lamination, layer turbulence, deformation features, etc.) could be better identified in open air outcrops, and that such features are less observable in borehole-wall scans and even less in the acquired samples. Thus, without establishing context from several nearby outcrops and remote-based regional data, our ability to understand geological history on Mars, even with sophisticated sample analysis, is much more difficult. Meter-scale vertical outcrops, which are abundant at the analogue wadis we studied, provided such context in detail that might be around, or just below, the limit of resolution of martian data.

The mineral-type identification is made difficult by claysized small grains that often attach to the surface of larger grains, while even weak fragmentation (during transport, e.g.) could separate most of these attached grains. This difference with regard to the presence of attached small grains is true not only for optical but for IR and Raman methods as well, as loss of the attached grains supports the acquisition of clear phases spectra, for example, for ExoMars rover's analysis.

Shallow subsurface exploration can provide useful information on the geological history of a given terrain even when materials can only be investigated to relatively shallow depths. In our work, which involved roughly 20 -cm-deep subsurface excavations, four of six locations investigated provided a distinctly different assessment of structure and lithology than was indicated by surface interrogation, and this helped to facilitate reconstruction of geological events that had occurred at these analogue sites. This is demonstrated by the three examples below.

(1) At site No. 0403, the homogeneous small size (1$2 \mathrm{~cm}$ ) debris cover of "typical desert appearance" was transported by a large areal flood after an earlier lacustrine wet period when clay deposition occurred, despite the fact that the area looked like many other stony desert scenes at first sight.

(2) Site No. 0203 seemed at first to be a typical reg desert-type location, based solely on its surface appearance, that formed by in situ weathering. Shallow subsurface exploration, however, revealed no supporting bedrock, a finding that required consideration of another origin for the surface material.

(3) Site No. 2038 was once an ephemeral lake and exhibited few surface signatures of the lacustrine phase (mainly covered by thin sand sheet from the nearby dunes). Subsurface layering, however, revealed the occurrence of at least two cycles of sand/clay deposition in a wet environment.

These observations infer that shallow subsurface excavation can clarify important water-related questions on Mars, where earlier lake beds could be easily buried in the recent wind-dominated era.

In the present study, analogue investigation provided examples and lessons learned as to how ideal study sites can be targeted, where on-site analysis is important with regard to selection of targeted areas on 10-100 m distant scales. Ideal sites to sample, such as the latest fluvial episodes and locations where wet signatures are closest to the surface, could be better identified on-site by way of remote images alone. In our study, natural outcrops $0.5-1.0 \mathrm{~m}$ in height were consistently present at the eight fluvial channels analyzed and thus would have been difficult to identify on Mars from the available data alone. Such features, however, may be abundant on Mars and lying in wait for discovery.

Geological information on different spatial scales should be assessed in particular at the meter range with a series of observations. In an ideal workflow, orbital data, local outcrop scanning, borehole-wall analysis, and detailed sample inspection are also to be considered; however, more analogue work will be required for the development of such case studies that can positively influence mission scenarios with regard to the ideal sequence number and spatial arrangement of nearby natural open-air outcrops.

Astrobiology-relevant aspects of our study are important drivers for present and upcoming Mars missions such that context information will help to facilitate instrumental planning, sample preparation, and analysis optimization. With regard to future mission goals (ExoMars' subsurface drilling procedures and sample return), present and future Ibn Battuta on-site investigations will help to improve our capability in ideal site targeting and localization below the meter spatial scale.

\section{Acknowledgments}

The field work and site access were supported by the Trans National Access project of the Europlanet RI (H2020 fund), while the related laboratory work was supported by the COOP-NN-116927 by NKFIH and the GINOP-2.3.2-152016-00003 funds, the Mars-related aspects gained information through COST TD1308. Europlanet 2020 RI has received funding from the European Union's Horizon 2020 research and innovation programme under grant agreement number 654208 .

\section{Author Disclosure Statement}

No competing financial interest exists in connection with this article from any of the authors.

\section{References}

Amador, E.S., Cable, M.L., Chaudry, N., Cullen, T., Gentry, D., Jacobsen, M.B., Murukesan, G., Schwieterman, E.W., Stevens, A.H., Stockton, A., Yin, C., Cullen, D.C., and Geppert, W. (2015) Synchronous in-field application of life-detection techniques in planetary analog missions. Planet Space Sci 106:1-10. 
Arvidson, R., Adams, D., Bonfiglio, G., Christensen, P., Cull, S., Golombek, M., Guinn, J., Guinness, E., Heet, T., Kirk, R., Knudson, A., Malin, M., Mellon, M., McEwen, A., Mushkin, A., Parker, T., Seelos, F., Seelos, K., Smith, P., Spencer, D., Stein, T., and Tamppari, L. (2008) Mars Exploration Program 2007 Phoenix landing site selection and characteristics. $J$ Geophys Res 113, E00A03.

Baliva, A., Marinangeli, L., Piluso, E., Ori, G.G., and Ruscito, V. (1999) Minero-petrographic studies of a possible martian analogue environment: Specchio DI Venere Lake, Pantelleria Island (Italy). In Bulletin of the American Astronomical Society, DPS Meeting No. 31, id.47.04, American Astronomical Society.

Barlow, N.G., Farr, T., Baker, V.R., Bridges, N., Carsey, F., Duxbury, N., Gilmore, M.S., Green, J.R., Grin, E., Hansen, V., Keszthelyi, L., Lanagan, P., Lentz, R., Marinangeli, L., Morris, P.A., Ori, G.G., Paillou, P., Robinson, C., and Thomson, B. (2011) Community decadal panel for terrestrial analogs to Mars. In DPS Meeting No. 33, id.14.11, Vol 33, Bulletin of the American Astronomical Society, American Astronomical Society, p 1055.

Berczi, S., Hudoba, G., and Hegyi, S. (2007) Mars analog fluvial and desert processes in the pliocene hungary studied with Hunveyor [abstract 1068]. In 38th Lunar and Planetary Science Conference, Lunar and Planetary Institute, Houston.

Blum, M., Marriott, S., and Leclair, S. (2005) Fluvial Sedimentology VII, Blackwell Publishing, Malden, MA.

Bost, N., Ramboz, C., LeBreton, N., Foucher, F., Lopez-Reyes, G., De Angelis, S., Josset, M., Venegas, G., Sanz-Arranz, A., Rull, F., Medina, J., Josset, J.-L., Souchon, A., Ammannito, E., De Sanctis, M.C., Di Iorio, T., Carli, C., Vago, J.L., and Westall, F. (2015) Testing the ability of the ExoMars 2018 payload to document geological context and potential habitability on Mars. Planet Space Sci 108:87-97.

Bridges, J.C., Seabrook, A.M., Rothery, D.A., Kim, J.R., Pillinger, C.T., Sims, M.R., Golombek, M.P., Duxbury, T., Head, J.W., Haldemann, A.F.C., Mitchell, K.L., Muller, J.-P., Lewis, S.R., Moncrieff, C., Wright, I.P., Grady, M.M., and Morley, J.G. (2003) Selection of the landing site in Isidis Planitia of Mars probe Beagle 2. J Geophys Res 108:E001820.

Cabrol, N.A. and Grin, E.A. (1999) Distribution, classification, and ages of martian impact crater lakes. Icarus 142:160-172.

Cabrol, N.A., Wettergreen, D., Warren-Rhodes, K., Grin, E.A., Moersch, J., Diaz, G.C., Cockell, C.S., Coppin, P., Demergasso, C., Dohm, J.M., Ernst, L., Fisher, G., Glasgow, J., Hardgrove, C., Hock, A.N., Jonak, D., Marinangeli, L., Minkley, E., Ori, G.G., Piatek, J., Pudenz, E., Smith, T., Stubbs, K., Thomas, G., Thompson, D., Waggoner, A., Wagner, M., Weinstein, S., and Wyatt, M. (2007) Life in the Atacama: searching for life with rovers (science overview). $J$ Geophys Res 112:G04S02, doi:10.1029/2006JG000298.

Catling, D.C., Claire, M.W., Zahnle, K.J., Quinn, R.C., Clark, B.C., Hecht, M.H., and Kounaves, S. (2010) Atmospheric origins of perchlorate on Mars and in the Atacama. J Geophys Res 115:E00E11.

Christensen, P.R. (1986) The spatial distribution of rocks on Mars. Icarus 68:217-238.

Clark, B.C., Morris, R.V., McLennan, S.M., Gellert, R., Jolliff, B., Knoll, A.H., Squyres, S.W., Lowenstein, T.K., Ming, D.W., Tosca, N.J., Yen, A., Christensen, P.R., Gorevan, S. Brückner, J., Calvin, W., Dreibus, G., Farrand, W., Klingelhoefer, G., Waenke, H., Zipfel, J., Bell, J.F., Grotzinger, J., McSween, H.Y., and Rieder, R. (2005) Chemistry and mineralogy of outcrops at Meridiani Planum. Earth Planet Sci Lett 240:73-94.
Cooke, R., Warren, A., and Goudie, A. (1993) Desert Geomorphology, UCL Press, London, $526 \mathrm{p}$.

Coradini, A. and Orosei, R. (2011) The exploration of Mars: past and future. Mem Soc Astron Ital 82:321.

Di Iorio, T., De Sanctis, M.C., Capria, M.T., Federico, C., Ammannito, E., De Angelis, S., Boccaccini, A., Capaccioni, F., Carraro, F., Cerroni, P., Frigeri, A., Palomba, E., Piccioni, G., Battistelli, E., Coppo, P., Novi, S., Mugnolo, R., Pirrotta, S., Salatti, M., and De Astis, G. (2012) A miniaturized imaging spectrometer embedded in a drilling system: Ma_Miss [abstract 1097]. In International Workshop on Instrumentation for Planetary Missions, Technische Universität Berlin, Germany. Doran, P.T., Wharton, R.A., Des Marais, D.J., and McKay, C.P. (1998) Antarctic paleolake sediments and the search for extinct life on Mars. J Geophys Res 103:28481-28494.

Dorizon, S., Ciarletti, V., Plettemeier, D., and Benedix, W.S. (2016) Performance validation of the ExoMars 2018 WISDOM GPR in ice caves, Austria. Planet Space Sci 120:1-14.

Durand, M. and Bourquin, S. (2013) Criteria for the identification of ventifacts in the geological record: a review and new insights. C R Geosci 345:111-125.

Edgar, L.A., Gupsta, S., Rubin, D.M., Lewis, K.W., Kocurek, G.A., Anderson, R.B., Bell, J.F., Dromart, G., Edgett, K.S., Grotzinger, J.P., Hardgrove, C., Kah, L.C., Leveille, R., Malin, M.C., Mangold, N., Milliken, R.E., Minitti, M., Palucis, M., Rice, M., Rowland, S.K., Schieber, J., Stack, K.M., Sumner, D.Y., Williams, A.J., Williams, J., and Williams, R.M.E. (2014) A fluvial sandbody on Mars: reconstruction of the Shaler outcrop, gale crater, Mars [abstract 1648]. In 45th Lunar and Planetary Science Conference, Lunar and Planetary Institute, Houston.

El-Baz, F., Breed, C.S., Grolier, M.J., and McCauley, J.F. (1979) Eolian features in the Western Desert of Egypt and some applications to Mars. J Geophys Res 84:8205-8221.

Farr, T.G., Arcone, S., Arvidson, R.W., Baker, V., Barlow, N.G., Beaty, D., Bell, M.S., Blankenship, D.D., Bridges, N., Briggs, G., Bulmer, M., Carsey, F., Clifford, S.M., Craddock, R.A., Dickerson, P.W., Duxbury, N., Galford, G.L., Garvin, J., Grant, J., Green, J.R., Gregg, T.K.P., Guinness, E., Hansen, V.L., Hecht, M.H., Holt, J., Howard, A., Keszthelyi, L.P., Lee, P., Lanagan, P.D., Lentz, R.C.F., Leverington, D.W., Marinangeli, L., Moersch, J.E., Morris-Smith, P.A., Mouginis-Mark, P., Olhoeft, G.R., Ori, G.G., Paillou, P., Reilly, J.F., II, Rice, J.W., Jr., Robinson, C.A., Sheridan, M., Snook, K., Thomson, B.J., Watson, K., Williams, K., and Yoshikawa, K. (2002) Terrestrial analogs to Mars. The future of solar system exploration (20032013). Community contributions to the NRC solar system exploration decadal survey. In ASP Conference Proceedings, Vol. 272, edited by M.V. Sykes, pp 35-76, Astronomical Society of the Pacific.

Fassett, C.I. and Head, J.W. (2008) Valley network-fed, openbasin lakes on Mars: distribution and implications for Noachian surface and subsurface hydrology. Icarus 198:37-56.

Garvin, J.B., Mouginis-Mark, P.J., and Head, J.W. (1981) Characterization of rock populations on planetary surfacestechniques and a preliminary analysis of Mars and Venus. Moon Planets 24:355-387.

Golombek, M. and Rapp, D. (1997) Size-frequency distributions of rocks on Mars and Earth analog sites: implications for future landed missions. J Geophys Res 102:4117-4130.

Groemer, G., Gruber, V., Bishop, S., Peham, D., Wolf, L., and Högl, B. (2010) Human performance data in a high workload environment during the simulated Mars expedition "AustroMars." Acta Astronaut 66:780-787. 
Groemer, G., Soucek, A., Frischauf, N., Stumptner, W., Ragonig, C., Sams, S., Bartenstein, T., Häuplik-Meusburger, S., Petrova, P., Evetts, S., and Sivenesan, C. (2014) The MARS2013 Mars analog mission. Astrobiology 14:360-376.

Grotzinger, J.P., Gupta, S., Malin, M.C., Rubin, D.M., Schieber, J., Siebach, K., Sumner, D.Y., Stack, K.M., Vasavada, A.R., Arvidson, R.E., Calef, F., Edgar, L., Fischer, W.F., Grant, J.A., Griffes, J., Kah, L.C., Lamb, M.P., Lewis, K.W., Mangold, N., Minitti, M.E., Palucis, M., Rice, M., Williams, R.M.E., Yingst, R.A., Blake, D., Blaney, D., Conrad, P., Crisp, J., Dietrich, W.E., Dromart, G., Edgett, K.S., Ewing, R.C., Gellert, R., Hurowitz, J.A., Kocurek, G., Mahaffy, P.R., McBride, M.J., McLennan, S.M., Mischna, M.A., Ming, D., Milliken, R., Newsom, H., Oehler, D., Parker, T.J., Vaniman, D., Wiens, R.C., and Wilson, S.A. (2015) Deposition, exhumation, and paleoclimate of an ancient lake deposit, Gale crater, Mars. Science, 350:aac7575-1.

Grotzinger, J., Bell, I.I.I., Herkenhoff, K., Johnson, J., Knoll, A., McCartney, E., McLennan, S., Metz, J., Moore, J., Squyres, S., Sullivan, R., Ahronson, O., Arvidson, R., Joliff, B., Golombek, M., Lewis, K., Parker, T., and Soderblom, J. (2006) Sedimentary textures formed by aqueous processes, Erebus crater Meridiani Planum, Mars. Geology 34:1085-1088.

Grotzinger, J.P., Crisp, J., Vasavada, A.R., Anderson, R.C., Baker, C.J., Barry, R., Blake, D.F., Conrad, P., Edgett, K.S., Ferdowski, B., Gellert, R., Gilbert, J.B., Golombek, M., Gómez-Elvira, J., Hassler, D.M., Jandura, L., Litvak, M., Mahaffy, P., Maki, J., Meyer, M., Malin, M.C., Mitrofanov, I., Simmonds, J.J., Vaniman, D., Welch, R.V., and Wiens, R.C. (2012) Mars Science Laboratory mission and science investigation. Space Sci Rev 170:5-56.

Hargitai, H. (2009) Collaborative online knowledge base for human planetary mission simulation stations [EPSC2009EPSC2491]. In European Planetary Science Congress, Europlanet RI.

Hesse, R. (2012) Short-lived and long-lived dust devil tracks in the coastal desert of southern Peru. Aeolian Res 5:101-106.

Hock, A.N., Cabrol, N.A., Dohm, J.M., Piatek, J., Warren-Rhodes, K., Weinstein, S., Wettergreen, D.S., Grin, E.A., Moersch, J., Cockell, C.S., Coppin, P., Ernst, L., Fisher, G., Hardgrove, C., Marinangeli, L., Minkley, E., Ori, G.G., Waggoner, A., Wyatt, M., Smith, T., Thompson, D., Wagner, M., Jonak, D., Stubbs, K., Thomas, G., Pudenz, E., and Glasgow, J. (2007) Life in the Atacama: a scoring system for habitability and the robotic exploration for life. J Geophys Res 112:G04S08.

Hugget, R.J. (2007) Fundamentals of Geomorphology, Routledge, London and New York, p 235.

Hynek, B.M. (2004) Implications for hydrologic processes on Mars from extensive bedrock outcrops throughout Terra Meridiani. Nature 431:156-159.

Jolliff, B., Moersch, J., Knoll, A., Morris, R., Arvidson, R., Gilmore, M., Greeley, R, Herkenhoff, K., McSween, H., and Squyres S. (2002) Remotely-sensed geology from landerbased to orbital perspectives: results of fido rover field tests. $J$ Geophys Res 107, E001470.

Kereszturi, A. (2012) Landing site rationality scaling for subsurface sampling on Mars-case study for ExoMars Roverlike missions. Planet Space Sci 72:78-90.

Kereszturi, A., Bradak, B., Chatzitheodoridis, E., and Ujvari, G. (2016) Indicators and methods to understand past environments from ExoMars Rover drills. Orig Life Evol Biosph 46:435-454.

Komatsu, G., Ori, G.G., Marinangeli, L., and Moersch, J.E. (2007) Playa environments on Earth: possible analogs for Mars. In The Geology of Mars: evidence from Earth-Based
Analog, edited by M.G. Chapman, Cambridge University Press, Cambridge, UK, p 322.

Levy, J.S., Head, J.W., and Marchant, D.R. (2009) Cold and dry processes in the Martian Arctic: geomorphic observations at the Phoenix landing site and comparisons with terrestrial cold desert landforms. Geophys Res Lett 36:L21203.

Losiak, A., Gołębiowska, I., Orgel, C., Moser, L., MacArthur, J., Boyd, A., Hettrich, S., Jones, N., and Groemer, G. (2014) Remote science support during MARS2013: testing a mapbased system of data processing and utilization for future long-duration planetary missions. Astrobiology 14:417-430.

Mabbutt, J.A. (1977) Desert Landforms, Australian National University Press, Cambridge, MA.

McKay, C.P., Friedmann, E.I., Gómez-Silva, B., CáceresVillanueva, L., Andersen, D.T., and Landheim, R. (2002) Temperature and moisture conditions for life in the extreme arid region of the atacama desert: four years of observations including the El Niño of 1997-1998. Astrobiology 3:393-406. McSween, H.Y., Murchie, S.L., Britt, D.T., Brückner, J., Dreibus, G., Economou, T., Ghosh, A., Golombek, M.P., Greenwood, J.P., Johnson, J.R., Moore, H.J., Parker, T.J., Rieder, R., Singer, R., and Wänke, H. (1999) Chemical, multispectral, and textural constraints on the composition and origin of rocks at the Mars Pathfinder landing site. J Geophys Res 104:8679-8716.

Milliken, R.E. (2015) The nature of hydrated minerals on mars: linking orbital and rover observations to constrain the climatic evolution of Mars [abstract 2736]. In 46th Lunar and Planetary Science Conference, Lunar and Planetary Institute, Houston.

Nichols, G. (2009) Sedimentology and Stratigraphy, WileyBlackwell, Oxford.

Nicoll, K. and Komatsu, G. (1999) Interpreting martian paleoclimates from valley network morphologies: insights from terrestrial analogues in Egypt [abstract 1054]. In 30th Annual Lunar and Planetary Science Conference, Lunar and Planetary Institute, Houston.

O'Neil, W.J. and Cazaux, C. (2000) The Mars sample return project. Acta Astronaut 47:453-465.

Orgel, C.S., Kereszturi, Á., Váczi, T., Groemer, G., and Sattler, B. (2014) Scientific results and lessons learned from an integrated crewed Mars exploration simulation at the Rio Tinto Mars analogue site. Acta Astronaut 94:736-748.

Ori, G.G., dell'Arciprete, I., and Taj-Eddine, K. (2013) Analog sites for Mars missions II [abstract 4014]. In Past, Present and Future Missions to Mars Conference, American Institute of Aeronautics and Astronautics, Inc.

Ori, G.G., Dell'Arciprete, I., and Taj Eddine, K. (2014b) The Sahara as a large-scale Mars analogue and the activities of the Ibn Battuta Centre [abstract 1456]. In $8^{\text {th }}$ International Conference on Mars, California Institute of Technology (Caltech) in Pasadena, California.

Ori, G.G., Flamini, E., Dell'Arciprete, I., and Taj-Eddine, K. (2009) A Facility of the Agenzia Spaziale Italiana to Test Operations, Instruments and Landing Systems for Mars Exploration: the PLANLAB Project of the Ibn Battuta Centre at Marrakech (Morocco) [abstract 1587]. In 40th Lunar and Planetary Science Conference, Lunar and Planetary Institute, Houston.

Ori, G.G., Flamini, F., and Taj Eddine, K. (2015) Mars analogue activities: the Ibn Battuta Centre and the Sahara desert [abstract EPSC2015-EPSC2780]. In European Planetary Science Congress, Europlanet RI.

Ori, G.G., Sabbadini, R., and Komatsu, G. (2014a) Comparing environmental changes and habitability settings in the geological 
history of Sahara and Mars [abstract P11C-3774]. In American Geophysical Union, Fall Meeting.

Ori, G.G., Taj-Eddine, K., and Dell'Arciprete, I. (2011) The Ibn Battuta Centre (Marrakech, Morocco) for testing lander science, operations and landing systems [abstract 6006]. In Analogue Sites for Mars Missions: MSL and Beyond, Lunar and Planetary Institute, Houston.

Orzechowska, G.E., Kidd, R.D., Foing, B.H., Kanik, I., Stoker, C., and Ehrenfreund, P. (2011) Analysis of Mars analogue soil samples using solid-phase microextraction, organic solvent extraction and gas chromatography/mass spectrometry. Int J Astrobiol 10:209-219.

Parsons, A. and Abrahams, A.D. (1984) Geomorphology of Desert Environments, Springer, Netherlands, p 115.

Peeters, Z., Quinn, R., Martins, Z., Sephton, M.A., Becker, L., van Loosdrecht, M.C.M., Brucato, J., Grunthaner, F., and Ehrenfreund, P. (2009) Habitability on planetary surfaces: interdisciplinary preparation phase for future Mars missions. Int $J$ Astrobiol 8:301-315.

Preston, L.J. and Dartnell, L.R. (2014) Planetary habitability: lessons learned from terrestrial analogues. Int J Astrobiol 13:81-98.

Rothschild, L.J. (1990) Earth analogs for martian life. Microbes in evaporites, a new model system for life on Mars. Icarus 88: 246-260.

Sephton, M.A., Court, R.W., Lewis, J.M., Wright, M.C., and Gordon, P.R. (2013) Selecting samples for Mars sample return: triage by pyrolysis-FTIR. Planet Space Sci 78:45-51.

Singer, C.S. (2012) Ultralight solar powered hybrid research drone [abstract 4059]. In Concepts and Approaches for Mars Exploration, Lunar and Planetary Institute, Houston.

Svendsen, A., van't Woud, H., Samurovic, D., Nebergall, K., Battler, M., Orgel, C., Stoker, C., Tolboom, I., and Foing, B.; Team EuroMoonMars. (2013) EuroMoonMars Field Campaign: geology traverse planning using orbital sub-m imagery. In $E G U$ General Assembly Proceedings, European Geosciences Union, Vienna, Austria, p 13616.

Svintsov, I.P. (2009) Development of sandy and stony deserts. In Agricultural Land Improvement: Amelioration and Reclamation, Vol. I, edited by B.S. Maslov, Eolss Publisher Co. Ltd., Oxford, p 316-337.

Thomas, S.D.G. (2016) The Dictionary of Physical Geography, John Wiley and Sons Ltd., Oxford.

Vago, J., Witasse, O., Svedhem, H., Baglioni, P., Haldemann, A., Gianfiglio, G., Blancquaert, T., McCoy, D., and de Groot, R. (2015) ESA ExoMars program: the next step in exploring Mars. Solar Syst Res 49:518-528.
Vago, J.L.; Exomars Project Team. (2010) The ExoMars Rover mission to search for signs of life [abstract 5318]. In Astrobiology Science Conference 2010: Evolution and Life: Surviving Catastrophes and Extremes on Earth and Beyond.

Warren-Rhodes, K., Weinstein, S., Dohm, J., Piatek, J., Minkley, E., Hock, A., Cockell, C., Pane, D., Ernst, L.A., Fisher, G., Emani, S., Waggoner, A.S., Cabrol, N.A., Wettergreen, D.S., Apostolopoulos, D., Coppin, P., Grin, E., Diaz, C., Moersch, J., Ori, G.G., Smith, T., Stubbs, K., Thomas, G., Wagner, M., and Wyatt, M. (2007) Searching for microbial life remotely: satellite-to-rover habitat mapping in the Atacama Desert, Chile. J Geophys Res 112:G04S05.

Weitz, C., Farrand, W., Jolliff, B., Johnson, J., Bell, J., and Yingst, A. (2006) Spectral diversity of rock fragments at the Meridiani Planum landing site [abstract P41B-1268]. In American Geophysical Union, Fall Meeting, San Francisco, CA.

Wells, S.G., McFadden, L.D., Poths, J., and Olinger, C.T. (1995) Cosmogenic 3He exposure dating of stone pavements: implications for landscape evolution in deserts. Geology 23: 613-616.

Wentworth, S.J., Gibson, E.K., Velbel, M.A., and McKay, D.S. (2005) Antarctic Dry Valleys and indigenous weathering in Mars meteorites: implications for water and life on Mars. Icarus 174:383-395.

Address correspondence to: Akos Kereszturi Konkoly Thege Miklos Astronomical Institute Research Centre for Astronomy and Earth Sciences H-1121, Konkoly Thege Miklos 15-17 Budapest Hungary

E-mail: kereszturi.akos@csfk.mta.hu

Submitted 24 March 2017 Accepted 04 July 2017

\section{Abbreviations Used \\ CLUPI $=$ close-up imager $\mathrm{IR}=$ infrared}

